\title{
On the socio-economic impact of pandemics in Africa Lessons learned from COVID-19, Trypanosomiasis, HIV, Yellow Fever and Cholera
}

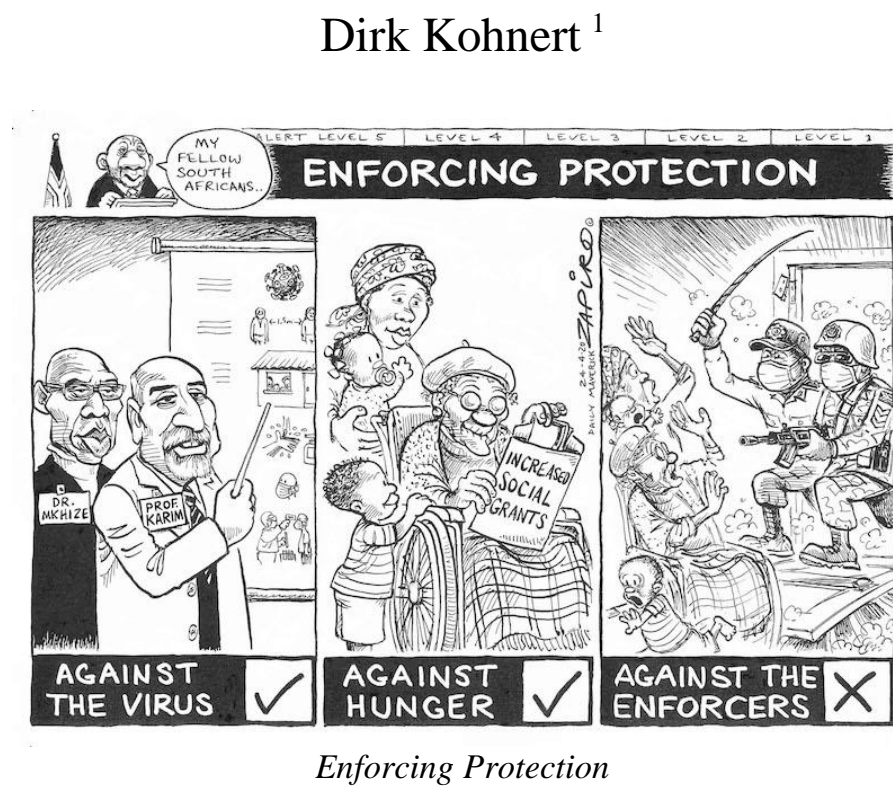

Source: Zapiro, Daily Maverick, 24 April 2020

\begin{abstract}
Throughout history, nothing has killed more human beings than infectious diseases. Although death rates from pandemics dropped globally by about $0.8 \%$ per year, all the way through the 20th century, the number of new infectious diseases like Sars, HIV and Covid-19 increased by nearly fourfold over the past century. In Africa, there were reported a total of 4,522,489 confirmed COVID-19 cases and 119,816 death, as of 23 April 2021. The pandemic impacted seriously on the economic and social sectors in almost all African countries. It is threatening to push up to $58 \mathrm{~m}$ people into extreme poverty. However, apart from the African poor, the Covid pandemic also affects the growing African middle class, i.e. about 170 million out of Africa's 1.3 billion people currently classified as middle class. Nearly eight million may be thrust into poverty because of the coronavirus and its economic aftermath. This setback will be felt for decades to come. Moreover, in recent African History also other infectious diseases like the 1896-1906 Congo Basin Trypanosomiasis with a death toll of over 500.000 as well as the 1900-1920 Uganda African trypanosomiasis epidemic with 200,000-300,000 death had a tremendous negative impact on Africa's societies and economies. Actually, other pandemics, like Yellow Fever, Cholera, Meningitis and Measles - not to mention Malaria - contributed to long-lasting economic downturns and seriously affect social wellbeing for decades.
\end{abstract}

Keywords: $\underline{\text { COVID-19, }}$ Corona, epidemics, Sub-Saharan Africa, socio-economics, migration, xenophobia, poverty, violence, ethics in epidemics, ethics dumping

JEL-Code: D62, D63, D74, E24, E26, F15, F22, F24, F35, F52, F54, H12, H51, I14, I15, J46, N37, N97, O14, O17, O55, Z13

\footnotetext{
${ }^{1}$ Associated expert at the GIGA Institute of African Affairs, Hamburg. Draft: May 6, 2021.
} 


\section{Introduction}

Throughout history, nothing has killed more human beings than infectious diseases. Although, death rates from pandemics dropped globally by about $0.8 \%$ a year, all the way through the 20th century, the number of new infectious diseases like Sars, HIV/AIDS and Covid-19 increased by nearly fourfold over the past century. In Africa, there were reported a total of 4,522,489 confirmed COVID-19 cases and 119,816 death, as of 23 April 2021. The pandemic impacted seriously on the economic and social sectors in almost all African countries. Colonialism contributed actively to the growth and increased impact of pandemics, as shown in case studies on Senegambia. French scientist at that time considered West Africa for example as a disease environment and Africans as carriers of infectious transmitters. The perception of the hot tropical climate, combined with outbreaks of epidemic diseases and seasonal allergies, were instrumental in the processes of urban transformation through hygienic measures such as waste removal, the closing of cemeteries, and the imposition of new building codes. However, the stigmatisation of African poor as 'filthy indigenes' led also to the forced removal of the urban poor - firstly from the city centres and later to their containment in isolated regions (Ngalamulume, 2021). Today, the COVID-19 pandemic is threatening to push up to $58 \mathrm{~m}$ people into extreme poverty. However, apart from the African poor, the Covid pandemic also affects the growing African middle class, i.e. about 170 million out of Africa's 1.3 billion people currently classified as middle class. Nearly eight million may be thrust into poverty because of the coronavirus and its economic aftermath. This setback will be felt for decades to come.

Moreover, in recent African History also other infectious diseases like the 1896-1906 Congo Basin Trypanosomiasis or sleeping sickness with a death toll of over 500.000 as well as the 1900-1920 Uganda African trypanosomiasis epidemic with 200,000-300,000 death had a tremendous negative impact on Africa's societies and economies. Actually, other pandemics, like Yellow Fever, Cholera, Meningitis and $\underline{\text { Measles }}$ - not to mention Malaria - contributed to long-lasting economic downturns and seriously affect social wellbeing for decades.

\section{Mayor epidemics and their impact on Africa's society and economy}

\subsection{COVID-19}

The Corona or COVID-19 pandemic claimed over 100,000 African lives and nearly 4 million cases have been recorded so far. However, Africa's pandemic is one of nuances, and not all countries are equally affected. Only 10 countries account for over $80 \%$ of all cases. Island nations suffer special impacts, rural-urban differentiation is evident, socioeconomic implications reveal gender biases, and trade patterns matter (UNDP, 2021).

A recent UNDP report analysed the long-term socio-economic impacts of COVID-19 across diverse African contexts and examined the effect COVID-19 will have on macro-economic development in 10 African countries by 2030 and 2050. The paper highlighted the 
multifaceted economic and social consequences of the COVID-19 pandemic across Africa, including on human development indicators, economic interdependence, and growth and resilience patterns. Changes in mortality, economic growth and international financial flows in Angola, Cabo Verde, Chad, DRC, Ethiopia, Kenya, Mali, Mauritius, Nigeria and South Africa are analysed in the document. Explicitly the report documents today's effects on country-level mortality, gross domestic product (GDP) growth and international monetary flows of trade, aid, foreign direct investment (FDI) and remittances. Its overall impact will shape long-term patterns of mortality, economic growth and international trade by 2030 and 2050. Moreover, the report unravels how these macroeconomic changes will affect socioeconomic indicators and human development by quantifying the outcomes for child mortality and poverty over the coming decades (UNDP, 2021).

The rapid spread of COVID-19 in Africa created a sense of urgency in Africa, and inspired calls for a coordinated global response to stop the pandemic, mitigating its devastating effects, and thus lay the foundation for long-term recovery (Ozili, 2020). Sociocultural norms and values that are at the centre of African societies now face a severe risk of disappearing into oblivion. The proliferation of social media spaces and other outlets of communication of professional and non-professional sources led to misinformation and deliberate disinformation with adverse consequences on the fight against the pandemic.

All these immediate challenges will have a long-lasting impact stretching into the post-pandemic period. It will have serious consequences for a sector that had already historically to suffer from structural weakness, including poor government financing (UNESCO, 2021).

Figure 1: Development of COVID-19 epidemic in different African countries from March 2020 to April 2021

The number of active cases by country.[22][23][24][25][26][27][28][29][30][31][32][33]

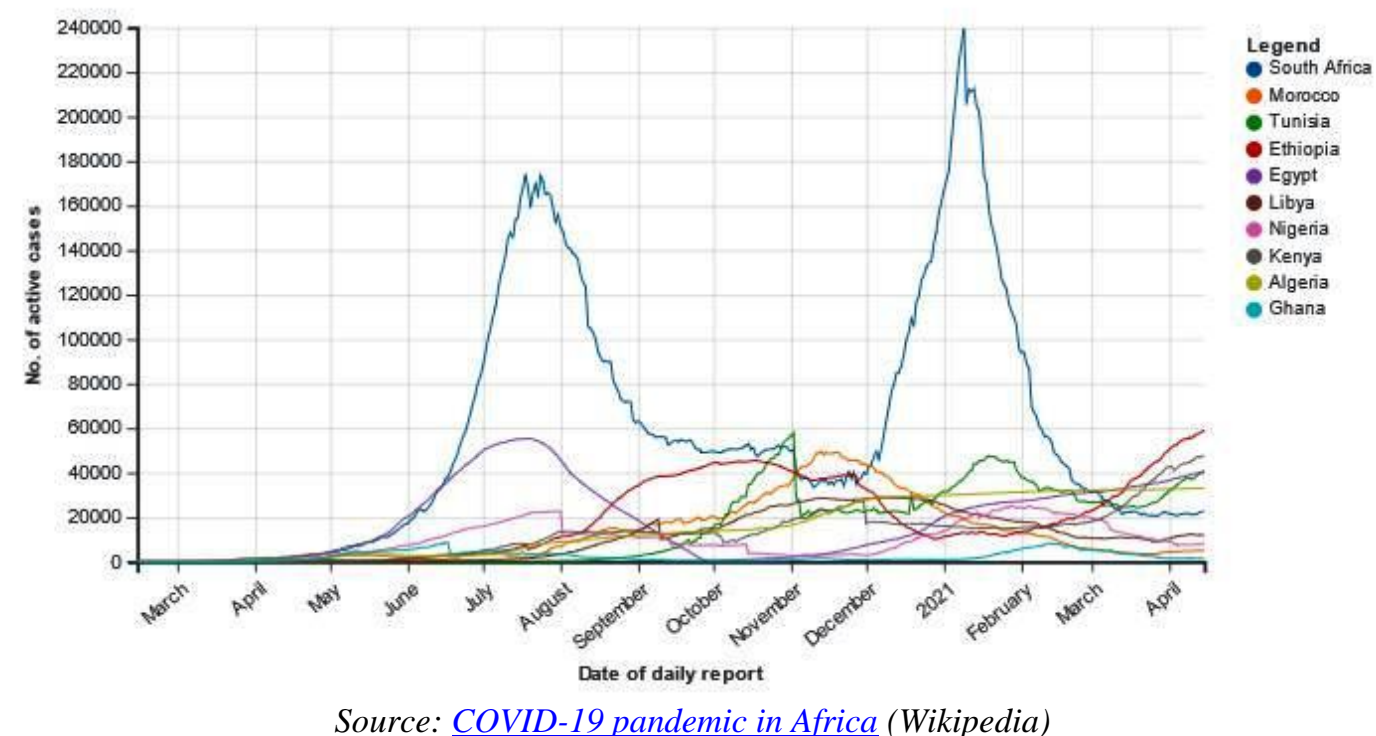

Source: COVID-19 pandemic in Africa (Wikipedia)

The pandemic had an impact on the cultural and informal sector as a whole. The restrictive measures led to the cancellation of major arts and cultural events, including festivals and conferences across the continent. It disrupted business, particularly of small and mediumsized enterprises (SMEs) operating in the informal and culture sector, and thus endangered major sources of livelihood for young and aspiring entrepreneurs. The epidemic revealed not 
only the fragility of healthcare systems all over Africa but it exposed also the need for more robust, high capacity science, technology as well as innovation ecosystems. The unavailability of Personal Protective Equipment (PPE), inadequate training of healthcare workers, lack of adequate facilities for the treatment of infected patients, are all factors that contributed to undermining the image and capacity of the African scientific community. The immediate and long-term consequences of school closures is likely to further augment inequalities in education.

In general, the coronavirus disease (COVID-19) and the attempts to limit its spread resulted in profound economic impacts, and a significant contraction in the global economy. A recent World Bank study (Josephson \& Kilic \& Michler, 2020) provided first scientific evidence on the socio-economic impacts of and responses to the pandemic among households and individuals in four case studies from Sub-Saharan Africa, based on household survey data from Ethiopia, Malawi, Nigeria, and Uganda. The appraisal was based on pre-COVID-19 face-to-face household surveys and additional novel phone surveys being conducted during the pandemic. The major findings were fourfold. First, although false beliefs about the Coronavirus and epidemic remained prevalent, government action to limit the spread of the disease was associated with greater individual knowledge of the disease and increased uptake of precautionary measures. Second, 256 million individuals -- $77 \%$ of the population in the four countries -- were estimated to live in households that had lost income due to the pandemic. Third, attempts to cope with this loss were exacerbated by the inability to access medicine and staple foods among $20 \%$ to $25 \%$ of the households in each country. Food insecurity was disproportionately borne by the African poor that were already impoverished before the pandemic. Fourth, student-teacher contact dropped from a pre-COVID-19 rate of $96 \%$ to just $17 \%$ among households with school-age children. The findings were meant to inform decisions by governments and international organizations on measures to mitigate the effects of the COVID-19 pandemic and they reveal the need for continued monitoring (Josephson \& Kilic \& Michler, 2020).

By the way, COVID-19 prevent and immunisation programs were evaluated favourably compared with similar programs in former epidemics in Africa. Despite all justified critique concerning Corona prevention, in no former time, authorities and the population would have been able to act as thoroughly and quickly. Millions more would have been infected and died without modern information technology and medicine. In the parlance of COVID-19 experts, to some extent, it was at least possible to "flatten the curve" (Malczycki, 2020).

After the decision of the United States and several European countries to suspend the use of the AstraZeneca vaccine in April 2021 because of the risk of blood clots, the authorities preferred to wait for the results of studies carried out by Western health agencies to give their green light. The returned doses were to be redistributed in May 2021 to four countries: Ghana, the Central African Republic, Senegal and Togo (Caramel, 2021).

\subsection{Trypanosomiasis / Sleeping sickness}

The appearance of the sleeping sickness or Human African Trypanosomiasis (HAT) corresponds largely to the range of the intermediate host of the virus, the tsetse fly, i.e. the area of 8 million km2 between 14 degrees North and 20 degrees South latitude. The species $\underline{T}$.

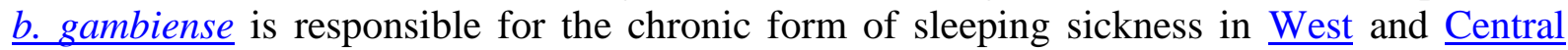

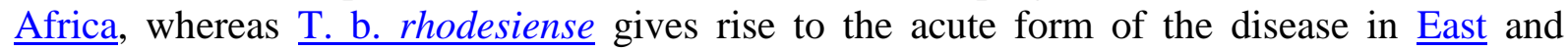


Southern Africa. If left untreated, sleeping sickness patients die within months when infected with T. b. rhodesiense or within years when infected with T. b. gambiense. Besides, wild and domestic animals may play a major role as parasite reservoirs for human infections with trypanosomes (Steverding, 2008). The history of HAT is closely linked to the slave trade. As sleeping sickness caused increasing losses, ship-owners and slave traders pressed their ship doctors to investigate the disease. Nevertheless, throughout the 19th century, reports on sleeping sickness increased and human African trypanosomiasis became a well-recognised disease, no one had any real idea about the nature of the illness nor effective cure.

Figure 2: Distribution of HAT in endemic countries, 2017 and 2018
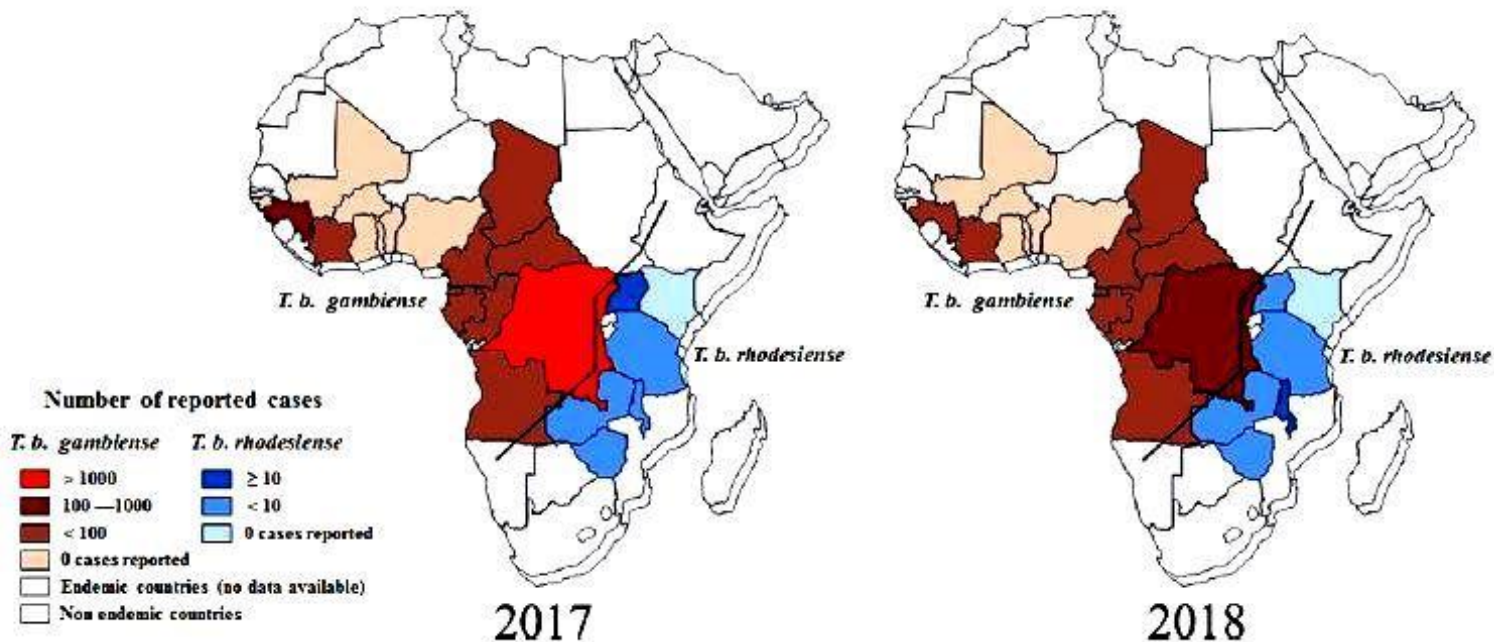

Source: Gaoe et al, 2020; $\underline{\text { WHO, } 2021}$

Figure 3: Deaths per 100,000 population due to HAT in 2002

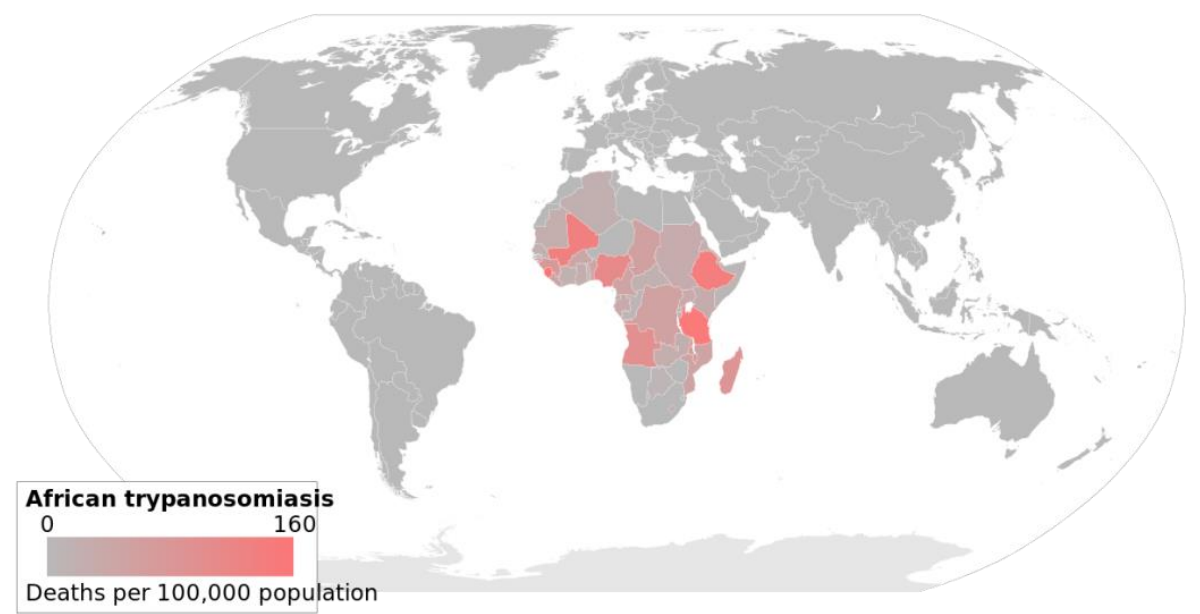

Source: Richard Wheeler (Zephyris), African trypanosomiasis, Wikipedia

At the turn of the $20^{\text {th }}$ century, there occurred three severe sleeping sickness epidemics. The first began in 1896 and lasted until 1906, It affected mainly the Congo Basin and Uganda, with 300,000 and 500,000 people estimated to have died in the Congo Basin and the Busoga focus in Uganda and Kenya, respectively (Steverding, 2008). The disastrous health and economic effects of the epidemic worried the colonial administrations to such an extent that they sent out scientific missions to investigate the disease and to develop a cure. However, it proved difficult to find effective drugs (e.g. Bayer-2005 and $\underline{\text { Suramin) }}$ that were available 
only in 1916. Both drugs helped to fight the second major sleeping sickness epidemic which began in several African countries in 1920 and died down by the late 1940s. Another important measure to control the 1920s sleeping sickness epidemic was the introduction of mobile teams to follow up the spread of the illness. The French colonial administration showed in Cameroon in 1926 the effectiveness of his approach. Within 11 years the prevalence levels of sleeping sickness declined from $60 \%$ in 1919 to $0.2-4.1 \%$ in 1930 . Subsequently, other colonial powers introduced the method of mobile teams for $T$. $b$. gambiense sleeping sickness control. A second approach, consisted in vector control, including included the use of differently designed traps and bush clearing, and host reservoir control and game destruction. Between 1920 and 1940, reservoir host control and game destruction resulted in a significant reduction, but never in the extermination, of the tsetse fly population. With the discovery of its insecticidal properties in 1939, DDT was used by 1949 in the hope of freeing large parts of endemic areas from tsetse flies (Steverding, 2008).

\section{Painting: "The sleeping sickness", by Gordon Ross (1873-1946) ${ }^{2}$}

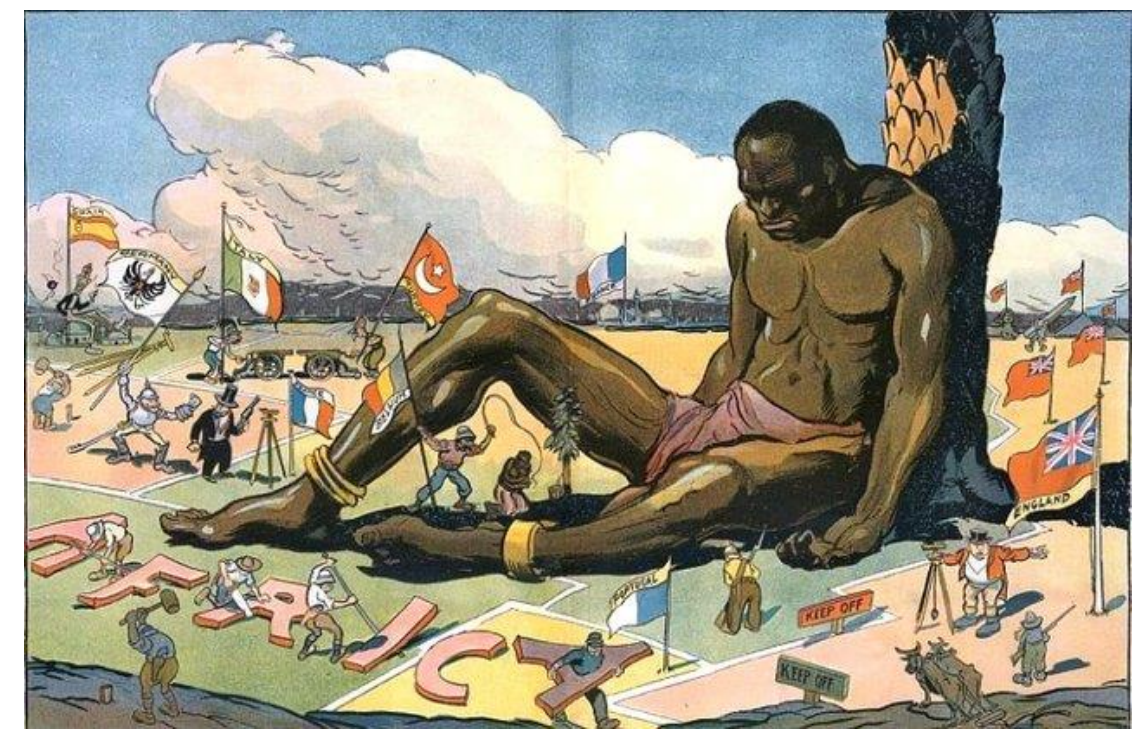

Source: Gordan Ross, 1873-1946, artist

N.Y. : Published by Keppler \& Schwarzmann, Puck Building, 1911 October $25^{3}$.

The socio-economic conditions of Colonial rule were another major driver of the spread of the sleeping sickness in Africa in the first half of the $20^{\text {th }}$ century. Colonial medcins and administration blamed for example the HAT for the demographic digression in the northcentral Uele district of the former Belgian Congo (Lyons, 1997). The Belgian as well as British colonialists commonly referred to their colonisation as a 'civilising mission', and many regarded the introduction of western bio-medicine as a central feature of their 'gift' to Africans. By 1930, however, it was clear that some features of their 'civilising mission' were in fact closely connected to the poor health of many of the Congolese. The Europeans introduced a harsh, repressive political system which, coupled with a ruthlessly exploitative economic system, led to the introduction of new diseases while already-existing diseases were

\footnotetext{
${ }^{2}$ Gordon Ross's allegory on the impact of colonialism in Africa shows a large African man in chains, affected by sleeping sickness, sitting, leaning against a tree, asleep, while several European countries are staking claims to portions of Africa. They are planting flags labelled England, Portugal, Belgium, Turkey, Italy, Germany, Spain, and France all around the sleeping man.

${ }^{3}$ Contributor Names: Ross, Gordon, 1873-1946, artist. - N.Y. : Published by Keppler \& Schwarzmann, Puck Building, 1911 October 25. - Source: Library of Congress Repository Library of Congress Prints and Photographs Division Washington, D.C.
} 
exacerbated and spread. Large numbers of Africans were displaced and many of them experienced famine. This created an ideal environment for spreading the disease and sleeping sickness became increasingly entrenched and epidemic. Moreover, many colonialists believed that much of the backwardness they saw in African society was attributable to endemic diseases, such as sleeping sickness, which could help to explain the lack of the use of the wheel and the attendant need for human porterage, or the lack of animal-powered ploughs, mills and the like (Steverding, 2008). Improvements in nutrition and hygiene after World War $\underline{I}$ are likely to have had as much to do with the decline of sleeping sickness as the medical interventions. By the 1930s, for example, many Africans in Belgian Congo no longer suffered from intense social and economic disruption and learned how to better cope with the rules and controls of the colonial powers. The Belgians on the other hand gradually ceased their social engineering practice of abrupt displacing whole communities.

Figure 4: The spread of sleeping sickness in Africa, 1939 - 2004.

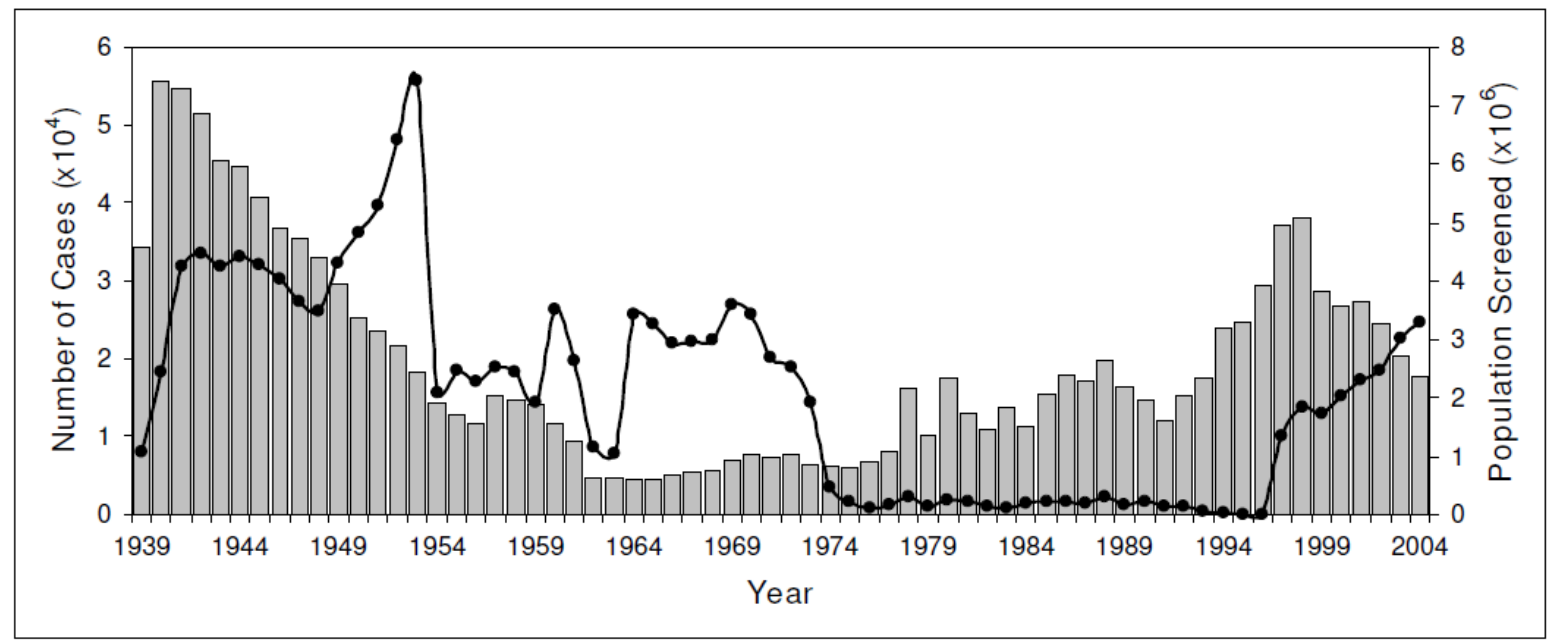

Number of reported cases of sleeping sickness and population screened, 1939-2004. Grey columns, number of reported cases; black circles, population screened (Steverding, 2008).

Figure 5: Number of reported cases of gambiense-HAT p.a. from 1990 to 2018 in endemic countries with a breakdown for each country

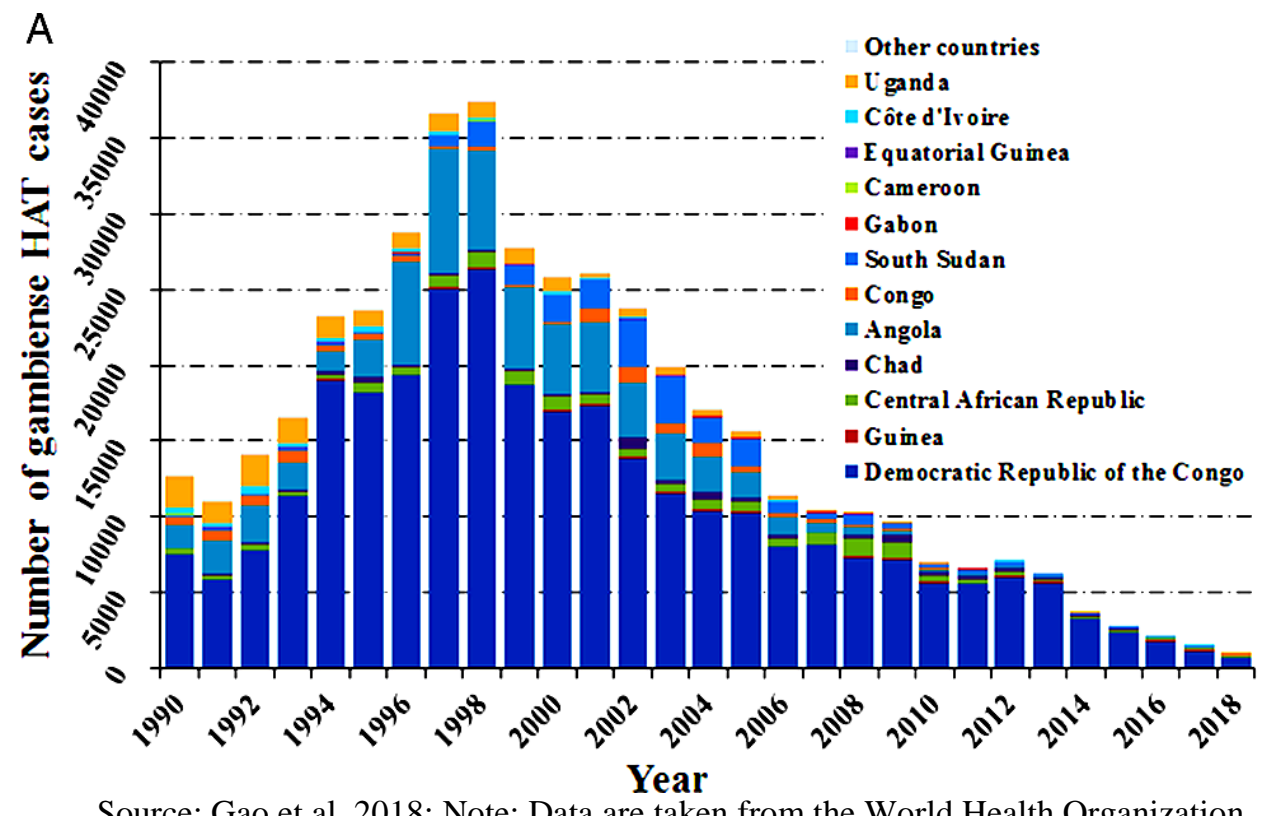


The sleeping sickness was also a major problem in Zambia already for centuries notably in the Eastern Province (Machila, 2013). During British colonial rule, the colonial administration tried to take appropriate measures to contain and prevent the spread of tsetse flies and trypanosomiasis with mixed results, when the British South African Company discovered the disease. The impact of the World War II limited the availability of resources for tsetse fly and trypanosomiasis control programmes which aggravated the situation. Only at the end of the war, in 1945, the colonial administration became actively involved in the control of the epidemic. All the while the indigenous people of Eastern Province continuously developed and readapted traditional survival strategies and ethnoveterinary medicines to cope with illness in their communities (Machila, 2013).

Figure 6: High-prevalence HAT areas in central Africa, 2000-2009

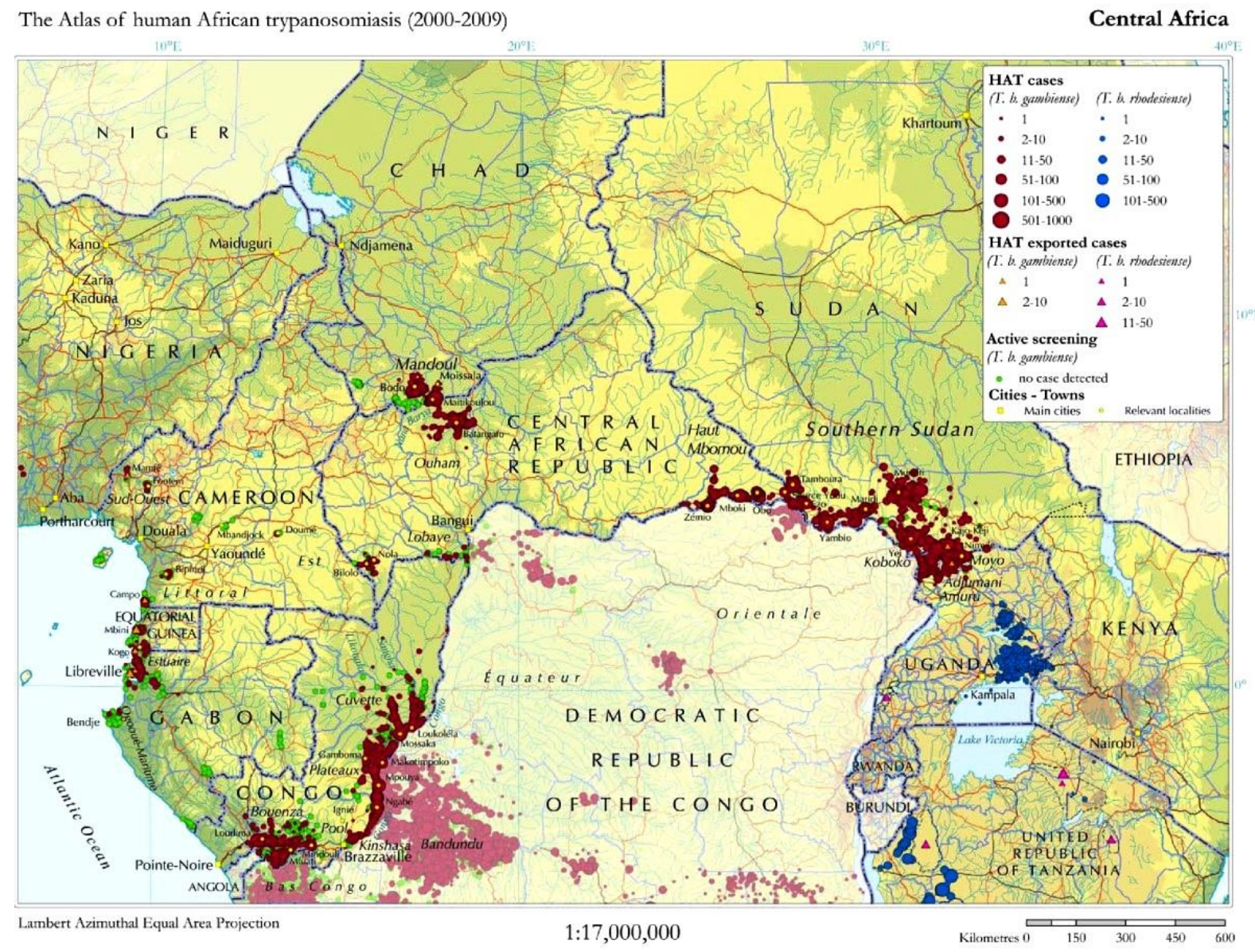

Source: Tong \& Valverde et al. (2011);

Reproduced under open-access attribution from Simarro PP et al. Int J Health Geogr 2010, 9:57

However, since the decolonisation of most African countries in the early 1960s, many African states experienced political instability and economic ruin with a disastrous effect on the health services. After a decade of low endemicity, the control of trypanosomiasis was no longer a priority. As a consequence, control programmes were stopped and population screening declined to very small numbers of people. Besides, concerns about the severe environmental effect of DDT led to a ban of the insecticide in the 1970s. As a result, there has been a steady increase in the number of reported sleeping sickness cases since the 1970s. This was the beginning of the third and most recent sleeping sickness epidemic, mainly affecting Angola, Congo, Southern Sudan and the West Nile district of Uganda. The situation remained unchanged until 1990. At the turn of the $20^{\text {th }}$ century, sleeping sickness had almost reached 
again the levels of the epidemics at the beginning of the century (Steverding, 2008). Fortunately, the World Health Organization (WHO) reached an agreement with the pharmaceutical companies Aventis (now Sanofi-Aventis) and Bayer AG in 2001 to provide sleeping sickness drugs free of charge for endemic countries. Médicins Sans Frontières was commissioned with the distribution of the drugs. Consequently, the number of new cases dropped steadily since 1998. At present, the estimated number of infected is estimated between 50,000 and 70,000.

Figure 7: Specific challenges of HAT control in conflict zones in DRC

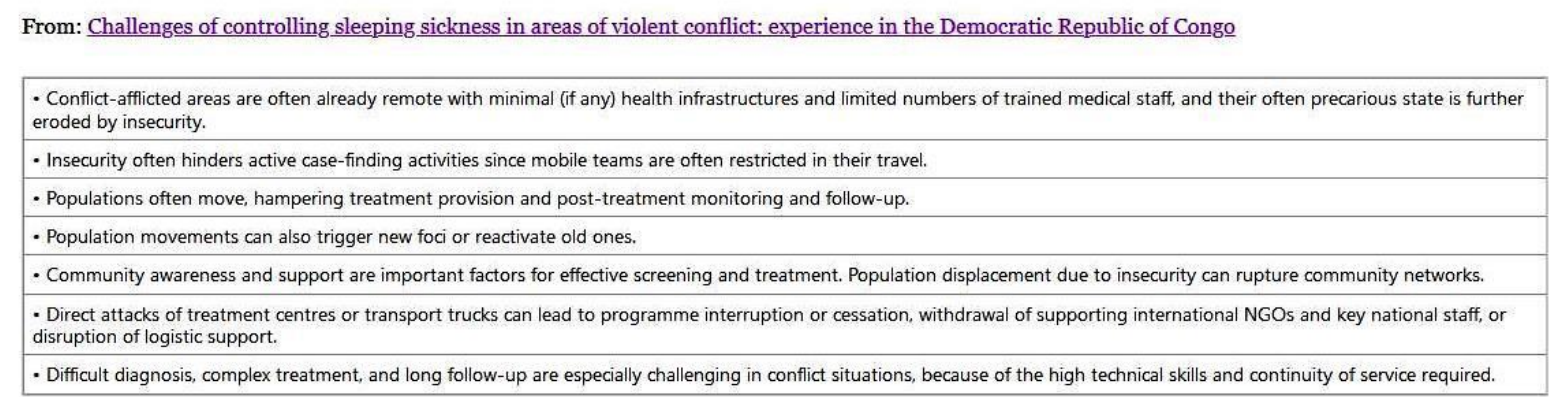

Source: Tong \& Valverde et al, 2011

Besides, the Organisation of African Unity ( $\underline{\mathrm{OAU}})$ launched 2001 the Pan African Tsetse and Trypanosomiasis Eradication Campaign (PATTEC) to eliminate the tsetse fly from Africa. The sterile male tsetse-fly technique was successfully used in the eradication of tsetse flies and consequently of the sleeping sickness in Zanzibar in 1997. However, in contrast to Zanzibar, infested with only one tsetse fly species, the PATTEC initiative had to deal with the much larger area of sub-Saharan Africa, inhabited by at least 7 different Glossina fly species recognised as vectors for transmission of sleeping sickness. Therefore, it is open to doubt whether the PATTEC approach would succeed as similar eradication campaigns failed in the past because the tsetse fly-infested areas could not be isolated. Last, but not least, the huge costs associated with the eradication project were also a concern, because most of the countries involved belong to the most heavily indebted poor countries in the world (Steverding, 2008).

A case study to assess the economic and social impact of HAT in Mambwe, $\underline{\text { Rufunsa, }}$ Mpika and Chama Districts of Zambia revealed various short- and long-term effects on livelihood and coping strategies of sleeping sickness victims, including physical and mental health effects, both on patients and affected community members (Mwiinde et al, 2017). Costs focussed on seeking treatment and hospitalisation. The average for those patients who spent money on treatment was less than half for female patients (US\$ 84) compared to males (US\$ 172). The money was used to purchase drugs for self-medication, for seeking treatment from traditional healers and for looking for treatment in private health care centres. Also, transport costs associated with seeking care for HAT patient were high, on average an amount of US\$ 99.3 had to be spent, which constituted a significant disincentive for seeking appropriate medical care (Mwiinde et al, 2017).

Another focus of the study was the evaluation of the impact of long-term disabilities of HAT, which were common. The impact was significant with the number of disability-adjusted life years (DALYs), increasing by between $44 \%$ and $50 \%$. Among the social consequences of HAT were misunderstanding, stigma, school dropout, pain, amnesia and disability. Acquired muscular and nerve deformity had a greater effect on females who often lost self-esteem. Both 
on community and family levels, stigmatisation, mental confusion, personality and behaviour changes led to school drop-outs, mortality, divorce or break-up of relationships, and resulted in an unfavourable climate for bringing up children. Mental confusion caused the victims not to associate with friends, while pain made the victims stay home, depriving them of social life (Mwiinde et al, 2017).

A second case study in Kenya and Uganda from 2004 to 2005 (usia, Teso and Bunqoma districts of western Kenya, and Busia and Teso districts of southeast Uganda between January 2004 and June 2005) revealed that health-seeking behaviour perpetuated the impact of HAT on affected individuals and households, that HAT disrupted the social functioning of households as well as the economic base of affected households (Bukachi et al-2007). Delayed diagnosis of HAT led to severe somatic effects on the patients. Mental effects were pronounced among young patients who subsequently faced difficulties fitting back into the community. Households suffered from financial burden as a result of seeking treatment from different health service providers. The illness was also sometimes attributed to HIV/AIDS or witchcraft. The latter caused victims to be stigmatized, delay the search for treatment or seek treatment from doubtful sources. Moreover, the disease led to conflicts within marriages, families and the community, thereby increasing the burden of women and children. Other economic impacts, were school drop-outs, school absenteeism, reduced productivity and increased funeral and burial expenses (Bukachi et al-2007; Pitlik, 2020). Finally, structural factors such as competing political interests, health worker strikes, inadequate budgetary allocations, economic opportunity, marginalization, illiteracy, entrenched cultural norms and practices, poor access to water, sanitation and housing, all served to propagate transmission (Ochola \& Karanja \& Elliott, 2021).

In addition, HAT deprived victims of opportunities to enhance their quality of life (e.g. by education) and resulted in the loss of personal income and friends. These findings corresponded with those of a WHO report which revealed that mental and behavioural disorders account for $17.6 \%$ of all disability in Africa. Some of these last for a few weeks or months while others may last a lifetime. Finally, limited awareness among community members and lack of prevention programmes resulted in a high HAT disease burden in rural communities. (Mwiinde et al. (2017) conclude, that HAT is a disease that emerges out of poverty both in terms of transmission dynamics and clinical outcomes, while simultaneously perpetuating and reinforcing a state of poverty among affected households. The disease affects households on multiple levels, including income generation, agriculture and food security, children's education and long-term health. At an individual level, the disease causes loss of self-esteem due to being stigmatised because of the acquired long-term physical and mental disabilities. 


\section{$2.3 \quad$ Yellow fever}

Yellow fever (YF), which originated in Africa and spread to South America in the $17^{\text {th }}$ century with the importation of African slaves by the Spanish and Portuguese slave traders as human cargo along with the Aedes aegypti mosquito carried in the bilges and buckets of slave vessels sailing from Africa to the New World (Oldstone, 2009: 103). Later on, the Aedes aegypti transmitted also other viruses like the Dengue, Zika and Chikungunya virus. In the 18th and 19th centuries, yellow fever was considered one of the most dangerous infectious diseases causing numerous epidemics all over the world. Till today it remains a major public health problem in Sub-Saharan Africa. Although a very effective vaccine is available for about 60 years, less than $2 \%$ of people are vaccinated because most African poor do not have access.

Figure 8: Areas with Risk of Yellow Fever Virus Transmission in Africa (2017)

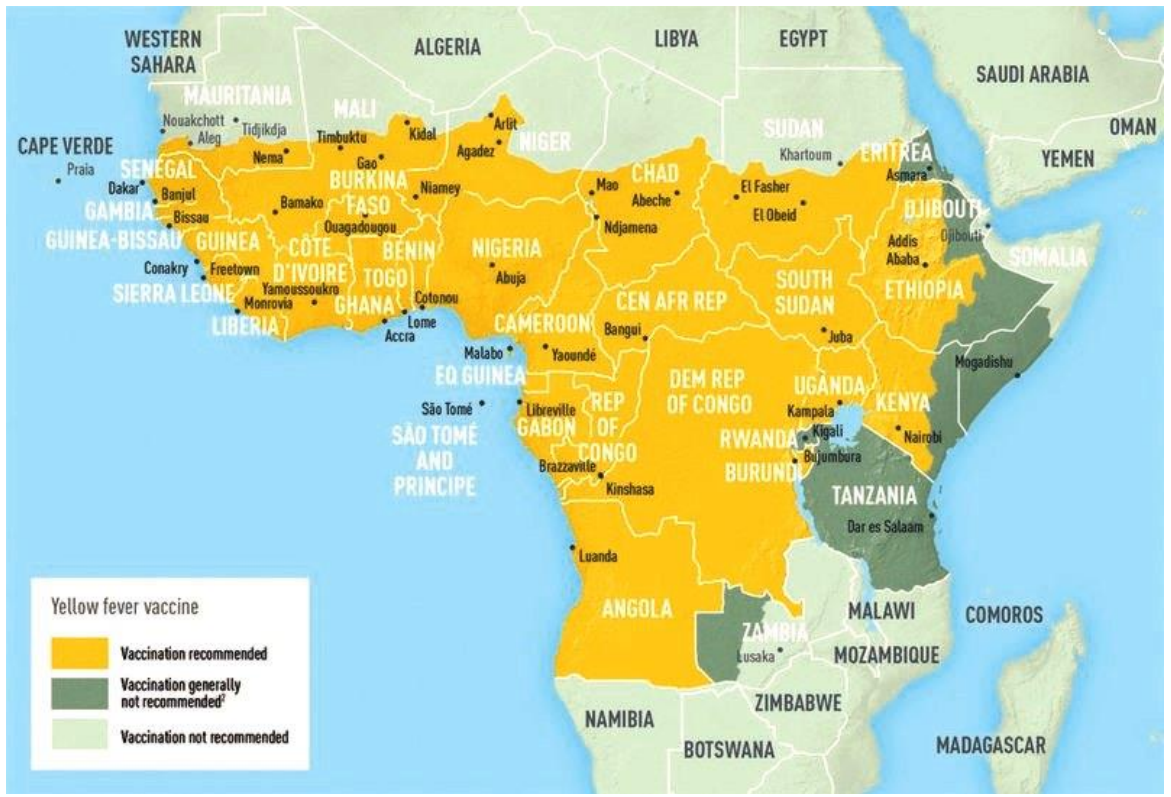

Source: Centers for Disease Control and Prevention [U.S. CDC], Atlanta, Georgia

According to WHO estimates about 200,000 victims p.a. become infected worldwide and 30,000 die p.a., but over $90 \%$ of cases occur in Africa. In the past 15 years, Yellow fever again increased tremendously, with most cases observed in West Africa.

Overall, there have been two major peaks of Yellow fever activity in Africa since 1948: one between 1960 and 1962, and the other between 1985 and 1995. The pike in the early 1960s was primarily due to the outbreak in Ethiopia, and the climax in 1985-1995 predominantly due to outbreaks in Nigeria. As a consequence of lagging Yellow fever vaccine distribution Nigeria is actually close to setting off an epidemic in the middle of the COVID-19 outbreak (Çavdaroğlu et al, 2021). Other African countries, like Ghana, Ethiopia, Congo, Guinea, may suffer a similar fat due to high migration rates of people and native fauna population. The Corona pandemic caused significant medical unattendance, besides the COVID-19 outbreak brought a significant growth of workload of hospital staff members, affecting patient management (Çavdaroğlu et al, 2021). 
The tremendous increase in Africa since the early 1980s reflects a major breakdown in YF control measures. The latter is due mainly to a breakdown of vaccination and mosquito control programs. Thus, in most cases in children under the age of 15, who got routine vaccinations, the programs were abandoned (Mutebi \& Barrett, 2020). In the past three years just in five West-African countries (Nigeria, Ivory Coast, Liberia, Senegal and Guinea) a total of 840 cases, including 216 deaths, were reported. Large Yellow fever epidemics, notably in East and Central Africa, occurred during periods of civil unrest (Sudan, Ethiopia) and largescale migration into endemic areas, e.g. in search of water in a period of drought. In contrast, epidemics in West Africa occurred without a similar mass movement of people into highly endemic areas.

Figure 9: Outbreaks and number of yellow fever cases, HO 1996 - 2001

\begin{tabular}{|c|c|c|c|c|}
\hline Year & Country & Location & Cases & Deaths \\
\hline 1995-1996 & Liberia & Buchanan & 359 & 9 \\
\hline 1996 & Benin & Atakora and Borgou & 86 & 65 \\
\hline 1996 & Ghana & Upper East Ghana & 27 & 5 \\
\hline 1997 & Liberia & Lofa County & 1 & 1 \\
\hline 1998 & Burkina Faso & Gaoua region & 2 & 1 \\
\hline 2000 & Nigeria & Kano State & 2 & \\
\hline 2000 & Liberia & Grand Cape Mount County & 102 & \\
\hline 2000 & Guinea & Northwest Guinea & 512 & 190 \\
\hline 2001 & Ivory Coast & & 203 & 21 \\
\hline 2001 & Guinea & & 18 & 2 \\
\hline 2001 & Liberia & & 3 & 3 \\
\hline Total & & & 1315 & 297 \\
\hline
\end{tabular}

Source: Mutebi \& Barrett, 2020, p.1460

Yellow fever provides insights into the evolution of public health interventions. Lessons learned for coping with the actual COVID-19 epidemic could be drawn from the health diplomacy implications of Yellow fever of how global health and international relations interact and influence each other. In controlling the disease, the early application of quarantine shifted to more coordinated approaches, which today include country vaccine entry requirements. Public health interventions directed at yellow fever have always been closely intertwined with economic and foreign-policy interests and frequently led to diplomatic tensions in the past, beginning with quarantines (Vanderslott \& Marks, 2020). Case studies in Ethiopia underscore also the role vector control could play in mitigating local disease transmission. The study emphasizes the urgent need to strengthen disease surveillance systems and in-country laboratory capacity to facilitate more rapid responses to future outbreaks of Yellow fever and other epidemics (Mulchandani, et al, 2019).

Figure 10: Aedes aegypti mosquito - wanted for the spread of Zika virus 'First, it was Yellow fever, then malaria. Darn right-wing media!'

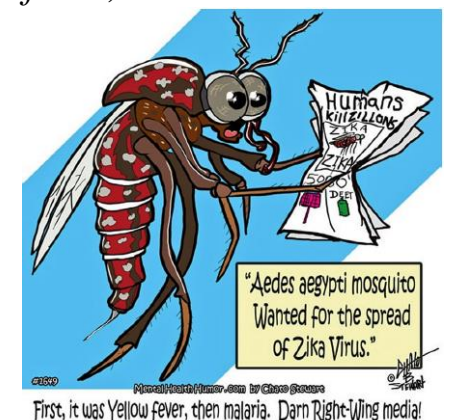

Source: Chato B. Stewart. The History of Zika. MentalHealthhumor.com, Saeed-2018, p. 147 


\subsection{HIV / Aids}

The human immunodeficiency virus (HIV) or acquired immunodeficiency syndrome (HIV/AIDS) infected over 60 million in the period of its greatest virulence (1983-2008) when nearly one half of them died (Oldstone, 2009: 252, chap. 14 HIV). The origin of HIV is said to be the close contact between humans and other infected primates and/or bats from which the illness was transmitted to humans in West- and Central Africa in the early-to-mid 20th century (Sharp \& Hahn, 2011). Like HIV, which spread to humans from monkeys, coronavirus jumped from an animal, in this case, a bat. The working theory is that Sars-Cov2 , the virus that causes Covid-19, probably leaped to people via a mammal, possibly a pangolin butchered at a wet market in the Chinese city of Wuhan (Pilling, 2020). Concerned were not only the direct victims but also their relatives, friends, communities had to suffer severely.

The HIV/AIDS epidemic is generally to be considered as a long-wave event compared with other epidemics. Mostly, the true death toll cannot be estimated until the full impact has been seen. It may take as long as 20 years before one can say that the world epidemic has peaked and/or begun to decline (Whiteside, 2002). As with most epidemics, AIDS has the potential to increase poverty. The causal chain runs from macro-economic factors, which result in poverty through the community, household and individual, into the capacity of the individual's immune system. That is protein-energy malnutrition, iron-deficiency anaemia, vitamin-A deficiency, all poverty-related conditions, decrease resistance to disease. Moreover, sexual behaviour - one of the major drivers of HIV - is in turn determined by economic, social and cultural factors. There are strong indicators that AIDS was originally spread by truck driver on major routes through Africa. They usually were away from home for long periods. They might have sex with a commercial sex worker because they are bored and feels their job is dangerous and they, therefore, deserve some compensation. Truck drivers are frequently away from their wife and family, and they might experience peer pressure from fellow drivers to engage in sex activity, last, but not least, because they have the necessary money (Whiteside, 2002). Commercial sex workers, on the other hand, were driven by poverty and the need to feed their family. Moreover, rapid economic growth, the concomitant growth of income inequality and the restructuring of economic sectors, with decreasing importance of the primary sector (agriculture, forestry and mining) and more weight of the secondary (manufacturing, electricity, gas, water and construction) and tertiary sector (all servicesbanking, insurance, trade and tourism), accelerate the spread of AIDS by disruption, deprivation, disease and death. Quick growth often disrupted traditional norms and cultures because people can not adapt so fast to the changes (Whiteside, 2002). Thereby, the unskilled are usually worst affected. Formal employment is declining, the informal sector is increasing.

Poverty assists HIV spread, and AIDS causes poverty. In effect, the epidemic is a development crisis. While a global effort is needed to advance technical inputs, like vaccines or treatment, to help to control the epidemic, there are no easy answers or simple technical and scientific solutions to dealing with its spread and impact. The most effective response is sustained and equitable development (Whiteside, 2002).

Meanwhile, antivirus drug therapy reduced the death rate by two-thirds compared to that in the United States during the 1990s. HIV therapy is a lifelong commitment last, but not least, because still there is no vaccine available. According to UN estimates, currently, over 34 million humans are infected with AIDS worldwide, but according to informed scholarly estimates, the real number is likely closer to 39 million. In Africa alone, the estimated HIV 
infection rate is $3 \%$ of the adult population. For a variety of reasons, victims do not seek medical care for as long as ten years after the initial infection, when they already have a compromised immune system and are seriously ill. In Africa over one in forty persons, both male and female, is infected.

Figure 11: Incidence of HIV in Africa per country, 2011

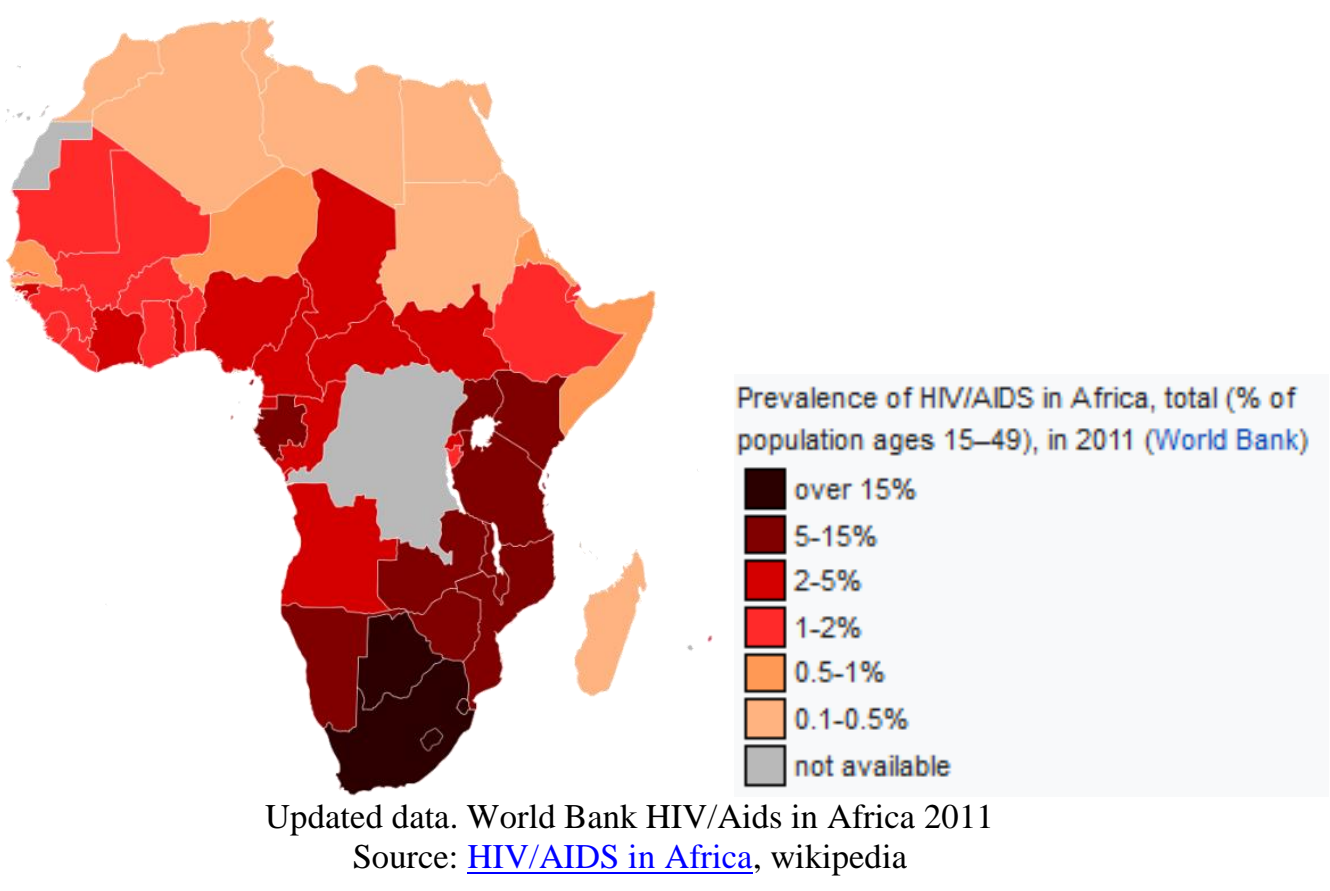

Figure 12: Global and sub-Saharan Africa prevalence of HIV from 2001, 2008-2015 (aged 15-49).

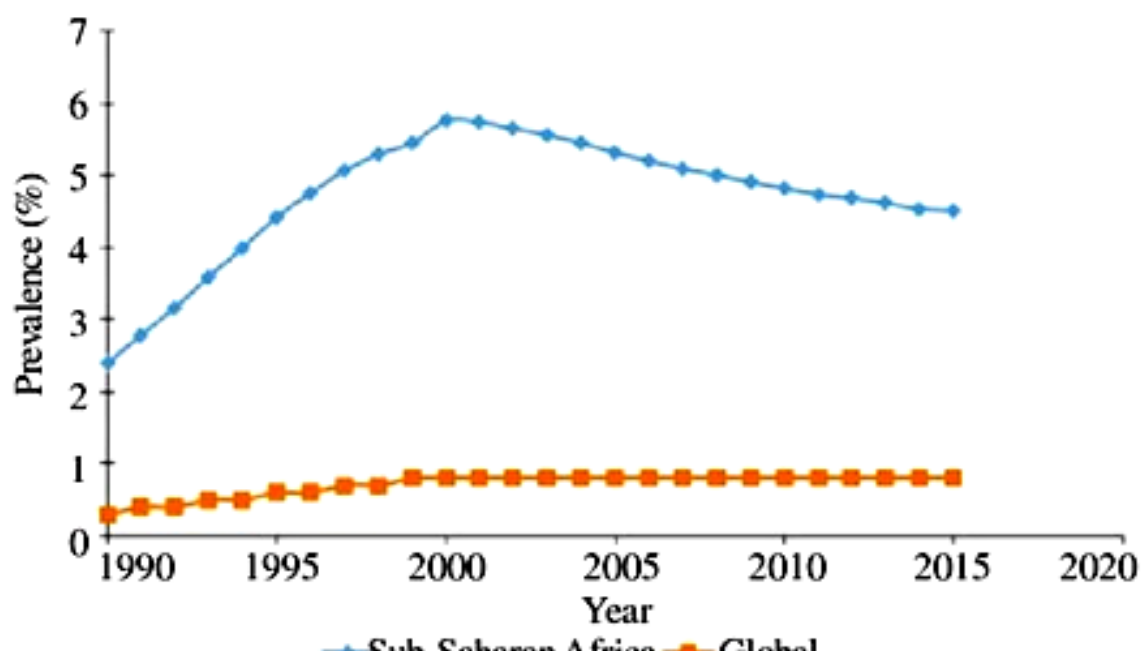

Source: Nweze \& Eke \& Nweze, 2017

The containment of AIDS is largely dependent on governance; i.e. what governments do or not do for their people. South Africa's dismal record in controlling HIV in the early stages of the epidemic was largely due to negligence and denial on all levels of government, including President Zuma. On the contrary, other African governments supplied at least education on safe sexual behaviour, testing for HIV, use of condoms and sterile needles. Some also 
provided antiretroviral drug therapy. These measures have dramatically reversed the incidence of and deaths from AIDS.

But customary cultural norms are difficult to change. The practice of having unprotected sex with multiple partners persist among many Africans. As usual, the poor and the vulnerable suffer most. African Women for example are three to four times more likely than men to become infected. Poverty and lack of facilities to care often force them to prostitute to survive. Moreover, traditional cultural bonds making multiple women nursing of new babies as well as FGM are long-lived. Health-care providers are scarce, with roughly one physician for nearly 40,000 people compared to one traditional faith healer per every 400 . The lack of treatment and adequate drugs for most of the 15,000 to 40,000 infected children in Cameroon for example made that only 400 received the drugs they needed in 2005 (Oldstone, 2009: 252, chap. 14 HIV).

Figure 13: Cartoon on the denial of SA President Jacob Zuma of the dangers of HIV ${ }^{4}$

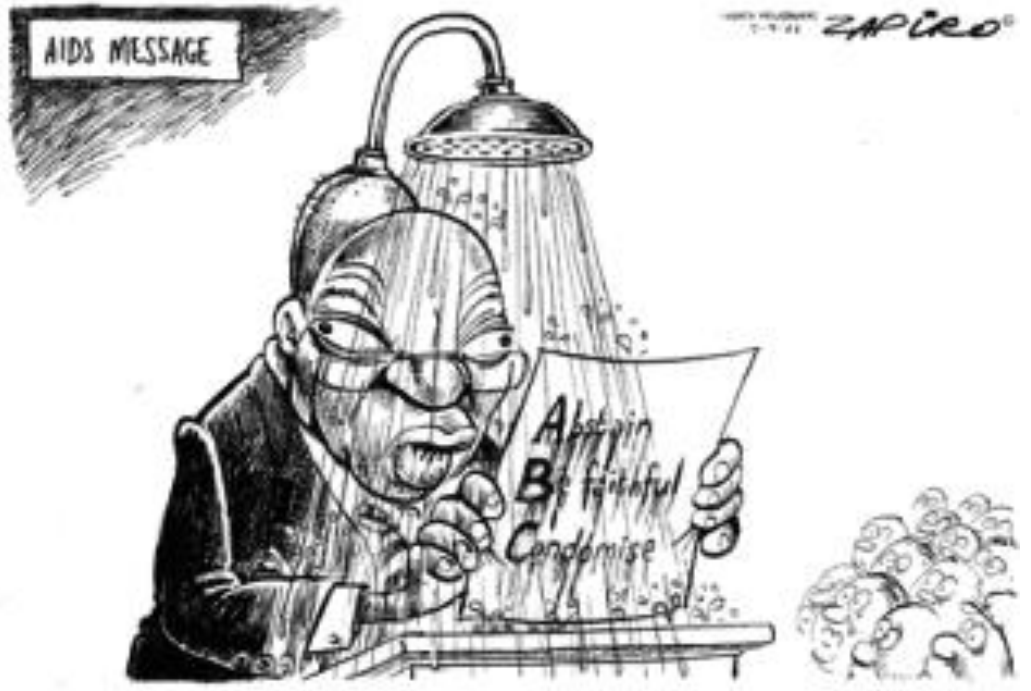

Source: Zapiro

Aids affected households had a higher burden of morbidity and mortality. Ill members were less likely to recover or to perform daily tasks. At least in South Africa with its relative advanced health sector, the use of public health care during illness apparently did not impose a major direct financial burden on households (Booysen, 2002). The cost of treatment and transport related to healthcare-seeking was relatively low, which proved that free government hospitals and clinics, which were the main pillars of South African health care, spared even poorer households from the major direct cost of illness. In contrast, funeral expenditure presented a substantial burden with a median of Rand 4,000-5,000 in the first wave of the epidemic and Rand 3,000-4,000 in the second ${ }^{5}$. Funerals had to be usually financed by their own income, either of the extended family or friends and via customary funeral insurance.

\footnotetext{
${ }^{4}$ The shower-head on than SA President Jacob Zuma was depicted by Zapiro to illustrate Zuma's ,, reputation as a disgraced, chauvinistic demagogue who cannot control his sexual needs and thinks a shower would protect against AIDS" - Zuma was accused of rape in 2005 which he was later acquitted of. He said that the sex was consensual and while he knew that the women with whom he had the affair were HIV positive. He told reporters that to minimize the risk of aids, he took a shower. This caused widespread controversy as HIV prevention advocates contested that the only way to avoid the spread of HIV was through abstinence and safe-sex practising and Zuma was not promoting the truth whatsoever." (Yoo, Philemon (2015): Jacob Zuma Political Cartoons by Zapiro. pyoo2, 29 Jan 2015) - Zapiro, an internationally renowned cartoonist, born as Jonathan Shapiro in Cape Town in 1958. website: http://www.zapiro.com/about/About_Zapiro/, accessed: April 29, 2021.

${ }^{5}$ The conversion rate of one Krugerrand (33.39 oz gold) to Euro in 2000 was $296 €$.
} 
Illness and death occurred mainly among household members of the economically active population (age 15-49), again emphasizing the adverse effect of the epidemic on the supply of labour in affected households.

Illness and especially mortality induced migration primarily of younger persons (i.e. teenagers). Persons that had left affected households were more likely to relocate to areas relatively close to home, while persons leaving non-affected families were more likely to relocate further from home for reasons mainly related to normal migration in the case of nonaffected households, i.e. employment, change of residence, marriage or education. In affected households, more than a third of members moved because of relatively uncommon migration reasons, e.g. to stay with parents, other family members or friends, or because of illness or death (Booysen, 2002). The departure of persons from affected households represented a relatively greater loss in terms of foregone monetary contributions than in the case of nonaffected households.

Affected households were poorer than non-affected families, regardless of whether measured in household income and expenditure or at the individual level. Affected households were also more dependent on non-employment income sources, which consisted primarily of government grants but also included the value of their subsistence production and consumption, while a smaller proportion of their income consisted of employment income. Affected households also spend less on food than non-affected households, both on aggregate and in per capita terms. In the long- run, this may have contributed to malnutrition amongst household members. The most frequent responses of households to financial crises seem to be borrowing, followed by the utilization of savings and the sale of assets. In more than $60 \%$ of cases money was borrowed from relatives and friends, while just about $20 \%$ of loans were obtained from money- or micro-lenders. The borrowed money was generally used to buy food. However, a larger proportion of affected families indicated that they used it for funerals and medical expenses, whereas the majority of non-affected families indicated that they used the money to pay for education, clothing and other expenses. The same applied for the considerable amounts of dissaving. Affected households utilized 21 (wave I) and 46 (wave II) months of current savings, whereas non-affected families utilized only 5 months of current savings. Coping financially in these ways was also more likely in rural than in urban areas, given that rural areas are generally poorer than urban areas. A death implied a much greater financial burden on a household than illness. In a worst-case scenario, the burden on affected households amounted to 3.4 to 4.3 times average monthly household income and 5.7 to 7.2 times average monthly household expenditure (Booysen, 2002).

The results of another case study on the impact of HIV/AIDS on farm women and their households in Enugu state (South-Eastern Nigeria) also significant negative socio-economic impact especially on the women and most vulnerable (Ugwu, 2009). Major effects were loss of feminine agricultural labour supply, reduced agricultural production and household income, increased family burden as well as loss of family assets and women's rights. The study emphasised the need for a gender-based paradigm to agricultural and rural development since women were at the centre stage of the HIV/AIDS epidemic in Nigeria as generally in Africa. 


\subsection{Cholera}

According to WHO estimates that each year there are 1.3 to 4.0 million cases of cholera, and 21000 to 143000 deaths worldwide due to cholera. In Africa alone, 40 to 80 million people live in Cholera hotspots. Climate change, urbanization, and population growth will likely increase the risk of cholera in the coming years. According to UN Habitat, the share of Africans living in urban areas is projected to grow from $36 \%$ in 2010 to $50 \%$ by 2030 . As a consequence, the number of slum dwellers in Sub-Saharan Africa will grow with the growth in the region's urban population. In 2010, already $60 \%$ of the urban population in subSaharan cities lived in slums. The pressure on infrastructure will therefore continue to increase, which is likely to worsen access to safe water and basic sanitation for the most vulnerable populations. Therefore, a global strategy on cholera control, ,Ending Cholera: a global roadmap to $2030^{\circ}$ was launched in 2017 to reduce cholera deaths by $90 \%$ (WHO, 2021: Ending Cholera - A Global Roadmap to 2030. WHO, Global Task Force on Cholera Control).

There were 499447 cases of cholera and 2990 deaths in 2018, according to reports from 34 countries. Nevertheless, the number of cholera cases decreased globally by $60 \%$ in 2018 , and the WHO hinted at an encouraging trend in cholera prevention and control in the world's major cholera hotspots, including Haiti, Somalia and the Democratic Republic of the Congo. According to the WHO, the decrease in several major cholera-endemic countries demonstrated the increased engagement of countries in global efforts to slow and prevent cholera outbreaks. This showed the vital role of mass cholera vaccination campaigns. However, the long-term solution for ending cholera lies in increasing access to clean drinking water and providing adequate sanitation and hygiene. While outbreaks are still ongoing in various countries, the caseload represents a significant downward trend in cholera transmission that has continued into 2019 („Drop in cholera cases worldwide, as key endemic countries report gains in cholera control“", WHO, 19 December 2019).

Nevertheless, Cholera remained a major public health problem in many African countries. In sub-Saharan Africa, 190,549 cases and 2,231 deaths were reported in 2014 according to the World Health Organization (WHO). Other informed estimates put the real number of deaths significantly higher up to 95,000 per year (Bwire et al, 2017). In the last twenty years, subSaharan Africa, and especially the Great Lakes Region, suffered the highest disease burden.

The high demands on African health services overburdened by the HIV/AIDS pandemic limited funding for cholera control. Furthermore, cholera is just one of many diarrhoeal diseases which as a group remain the second largest cause of childhood mortality and morbidity in the developing world. The current biotype of cholera, Vibrio cholerae El Tor has been established in Africa since 1972. Some of the greatest epidemics occurred in Mozambique, with peaks in 1993 and 1998.

Beyond unacceptable risks to life and livelihoods, these epidemic threats are indicators of other development issues, i.e. the close relationship between poverty and infectious diseases. Therefore, there is a need for more integrated disease risk assessments and responses that could face issues of health security and poverty reduction (Collins et al, 2006). People are socio-economically vulnerable when there is no livelihood security, when rights are denied, as a result of conflict, and through environmental disasters. Major human catastrophes, 
particularly rapid or slow-onset infectious disease epidemics, impact more heavily on the poor (Collins et al, 2006).

Cholera differs from many other forms of diarrhoea in that it can cause high numbers of cases and deaths over a very short period. For example, extreme cholera outbreaks took place in a

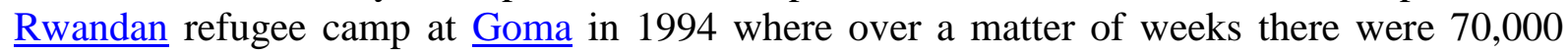
cholera cases and an estimated 12,000 deaths, giving a case fatality rate of $17.1 \%$. Furthermore, while cholera and diarrhoeal diseases thrive in conditions of poverty they can be further accentuated through beliefs, attitudes and hygiene practices that are indigenous to a particular region or culture. Recognition of socio-economic and behavioural influences alongside pathogenic and environmental hazards reveals risks that vary in nature from place to place over time. Therefore, many of the indicators for cholera risk management are also indicators of other health risks (Collins et al, 2006).

Figure 14: Map of the 2008-2009 cholera outbreak in sub-Saharan Africa showing the statistics as of 12 February 2009

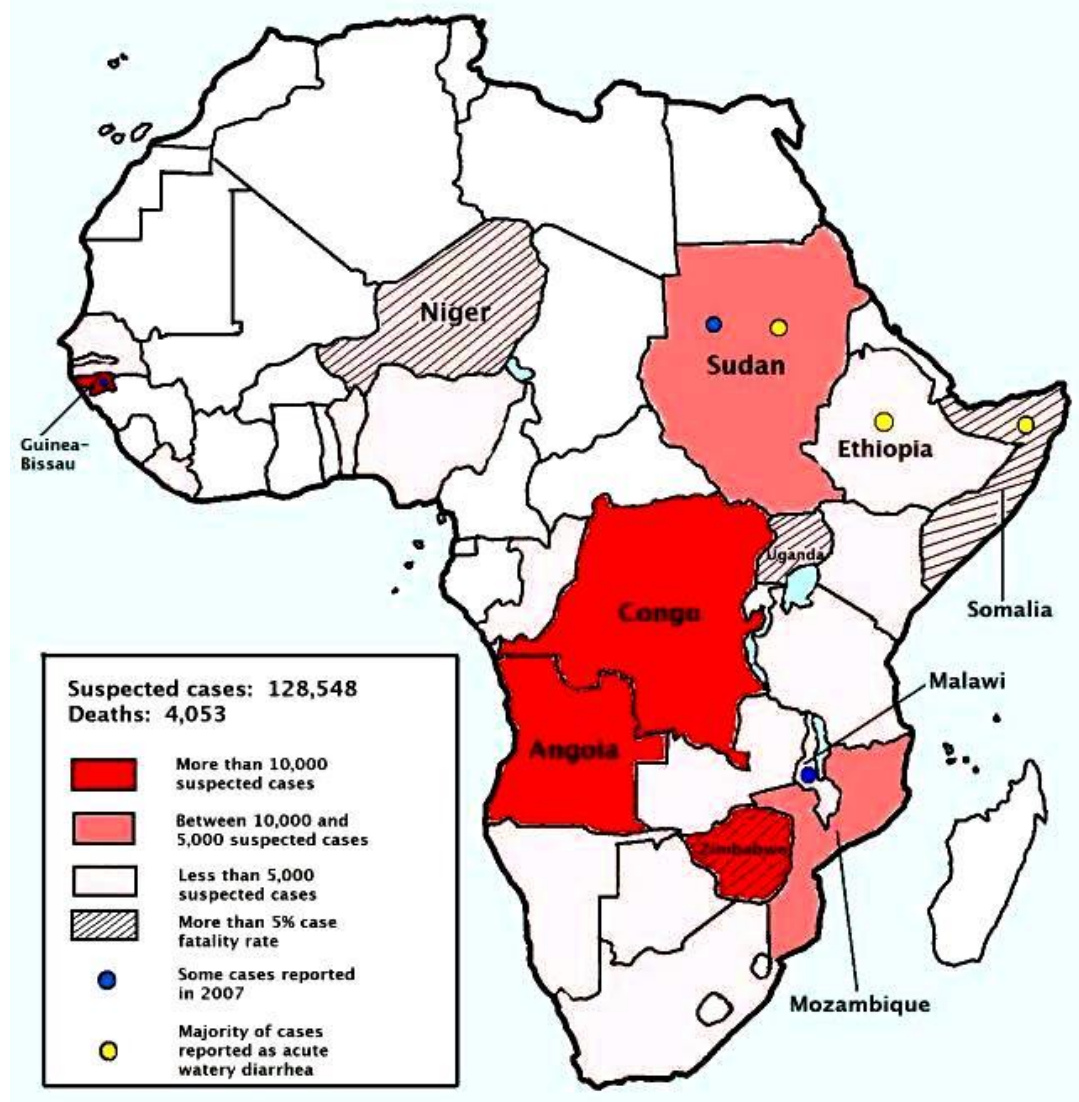

Source: Cholera, wikipedia

2.5.1. Case study on the socio-economic impact and politics of the 2008/09 cholera epidemic in Zimbabwe.

The cholera outbreak in Zimbabwe started in August 2008. It erupted in the impoverished high-density townships of Harare's metropolitan area. The epidemic rapidly spread through the country and finally crossed the borders into neighbouring countries. Within ten month it 
contaminated over 100,000 victims, claiming nearly 5,000 lives. Thereby it became the largest and most extensive cholera outbreak in recorded African history (Chigudu, 2017).

Figure 15: „Requesting permission to arrest all cholera sufferers, your Excellency“ 6

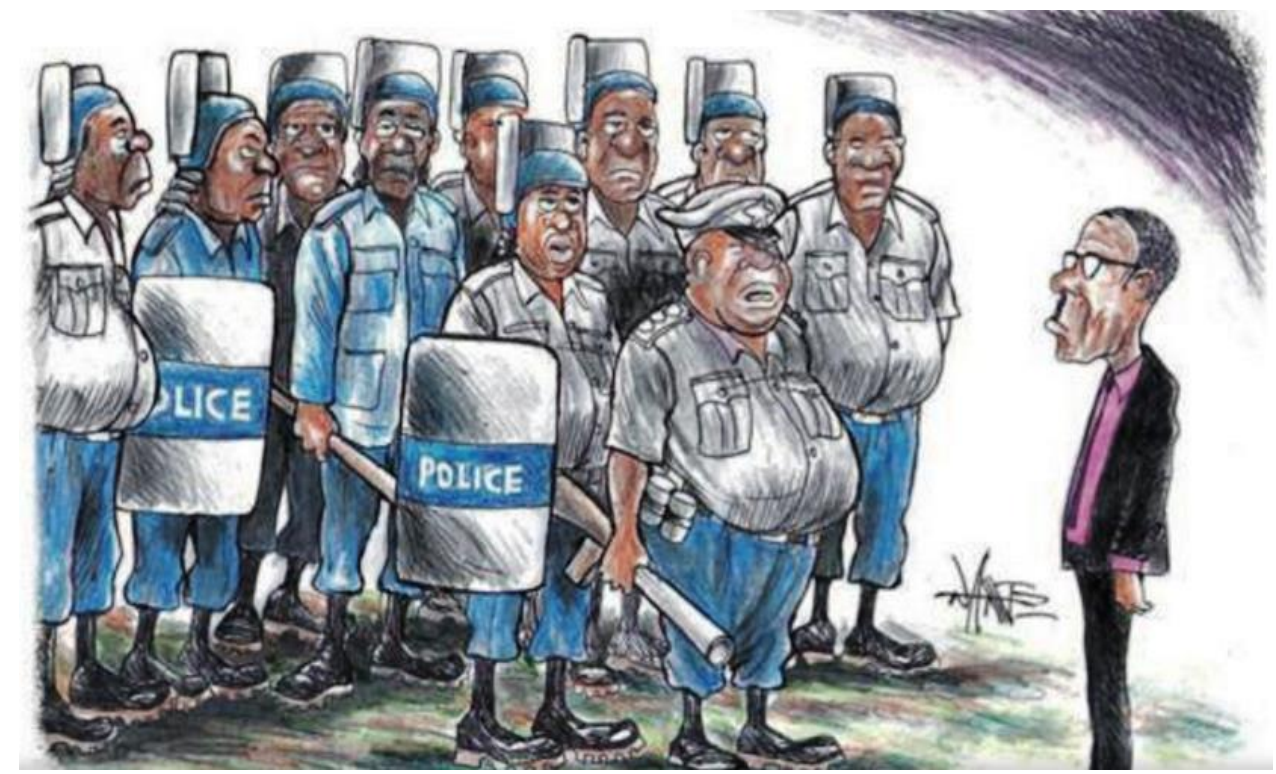

Source: Chigudu, S. (2017).

„State of emergency: the politics of Zimbabwe's cholera outbreak, 2008/09“

$[\mathrm{PhD}$ thesis]. University of Oxford.

Chigudu's thesis ,examines the politics of Zimbabwe's catastrophic cholera outbreak in 2008/09“, which caused an unprecedented 98,000 cases and over 4,000 deaths. Epidemiologically, the outbreak can be explained by the breakdown of the country's water and sanitation systems. Such a reading, however, belies the byzantine political, economic and historical processes that precipitated the dysfunction of the water systems, that delineate the socio-spatial pattern of the outbreak and that account for the fragmented and inadequate response of the national health system. The complex causal factors and the far-reaching consequences of the outbreak indicate that cholera is a unique prism through which to view different political phenomena including the dilemmas and contradictions of political change, bureaucratic order, humanitarianism, crisis and citizenship in Zimbabwe. Based on extensive field research, Chigudu argues first, ,that Zimbabwe's cholera outbreak was a 'man-made disaster. It was the final stage of both path-dependent and contingent processes rooted in questions of political economy such as the collapse of public health infrastructure, failing livelihood strategies and violent repression." Second, Chigudu argues ,that cholera reproduced and exacerbated a multiplicity of socio-political crises pertaining to the legitimacy of the Zimbabwean state, the nature of structural inequalities in Zimbabwean society and fundamental flaws in the global humanitarian response to epidemics." Third, Chigudu looks ,at the myriad meanings, memories and narratives the epidemic has left in its wake across public institutions and in civic life." Finally, Chigudu argues that „cholera has been committed to historical memory as a health crisis, a political-economic crisis, and a social crisis as well as a crisis of expectations, history and social identity.“(Chigudu, 2017).

\footnotetext{
${ }^{6}$ Tony Namates satirical cartoon of a police commander requesting permission from President Robert Mugabe to arrest all cholera sufferers. His cartoon was originally published by the daily The Guardian, Harare, on 27 December 2008. - Tony Namate is a Zimbabwean cartoonist who has gained international recognition for his scathing cartoon commentary on socio-political issues in Zimbabwe and beyond (Tony Namate, wikipedia).
} 


\section{Lessons Learned}

1) Early warning models and timely and sustainable monitoring of pandemics and potential hotspots even in post-epidemic times

2) Encouraging self-help as well as viable indigenous survival strategies and ethnoveterinary medicines to cope with the epidemic in the communities of victims. The African poor are largely dependent on their intimate knowledge of the environment passed on from generation to generation to control epidemics.

3) Disseminating model survival strategies and traditional medicine proved to be effective in the past or other regions

4) Focussing on:

(1) Mobile teams for combatting the pandemic in its hotspots more effectively

(2) Hotspots of the pandemic in the urban quarters of the poor and underprivileged (refugees, migrants etc.) where many victims live close together, without access to means of protection, medicine and medicaments

(3) Capacity-building of primary health care personnel to diagnose and to increase their awareness about the disease. Similarly, people at risk should be empowered to help them recognize the symptoms of the disease early and to be integrated back into the community (Bukachi et al-2007).

(4) As a long term strategy, improvements in education and reduction in poverty should contribute to epidemic prevention, control and elimination (Bwire et al, 2017).

5) In effect, epidemics are most often a development crisis. The most effective response is sustained and equitable development (Whiteside, 2002). 


\section{Appendix 1}

\section{(1) Mayor epidemics in Africa}

\section{- COVID-19 pandemic in Africa}

- The COVID-19 pandemic was confirmed to have spread to Africa on 14 February 2020, with the first confirmed case announced in Egypt. The first confirmed case in sub-Saharan Africa was announced in Nigeria at the end of February. Within three months, the virus had spread throughout the continent, as Lesotho, the last African sovereign state to have remained free of the virus, reported a case on 13 May. By 26 May, it appeared that most African countries were experiencing community transmission, although testing capacity was limited. Most of the identified imported cases arrived from Europe and the United States rather than from China where the virus originated.[8] It is believed that there is widespread under-reporting in many African countries with less developed healthcare systems. New strains of the virus were found in December 2020 in South Africa and Nigeria, in addition to the Lineage B.1.1.7 variant reported in the United Kingdom in September. Impact: Experts have worried about COVID-19 spreading to Africa, because many of the healthcare systems on the continent are inadequate, having problems such as lack of equipment, lack of funding, insufficient training of healthcare workers, and inefficient data transmission. It was feared that the pandemic could be difficult to keep under control in Africa, and could cause huge economic problems if it spread widely. The pandemic has had a serious economic impact in African countries, damaging the continent's growing middle class and threatening to increase the rates of poverty and extreme poverty. ('COVID-19 pandemic in Africa', Wikipedia)

\section{- HIV in Africa:}

- "HIV/AIDS originated in Africa in the early 20th century and is a major public health concern and cause of death in many African countries. AIDS rates vary dramatically although the majority of cases are concentrated in Southern Africa. Although the continent is home to about $15.2 \%$ of the world's population, more than two-thirds of the total infected worldwide - some 35 million people - were Africans, of whom 15 million have already died. Sub-Saharan Africa alone accounted for an estimated $69 \%$ of all people living with HIV and $70 \%$ of all AIDS deaths in 2011.In the countries of sub-Saharan Africa most affected, AIDS has raised death rates and lowered life expectancy among adults between the ages of 20 and 49 by about twenty years. Furthermore, the life expectancy in many parts of Africa is declining, largely as a result of the HIV/AIDS epidemic with life-expectancy in some countries reaching as low as thirtyfour years.

- Countries in North Africa and the Horn of Africa have significantly lower prevalence rates, as their populations typically engage in fewer high-risk cultural patterns that promote the virus' spread in Sub-Saharan Africa. Southern Africa is the worst affected region on the continent. As of 2011, HIV has infected at least $10 \%$ of the population in Benin, Botswana, Lesotho, Malawi, Mozambique, Namibia, South Africa, Eswatini, Zambia, and Zimbabwe.

- In response, a number of initiatives have been launched in various parts of the continent to educate the public - notably the youth - on HIV/AIDS. Among these are combination prevention programmes, considered to be the most effective initiative, such as the abstinence (proved to be difficult in a Muslim society), be faithful, use a condom campaign and the Desmond Tutu HIV Foundation's outreach programs.

- The number of HIV positive people in Africa receiving anti-retroviral treatment in 2012 was over seven times the number receiving treatment in 2005, with nearly 1 million added in the previous year:15 The number of AIDS-related deaths in Sub-Saharan Africa in 2011 was $33 \%$ less than the number in 2005.The number of new HIV infections in Sub-Saharan Africa in 2011 was $25 \%$ less than the number in 2001". (HIV in Africa, Wikipedia) 


\section{- Ebola}

- "The disease was first identified in 1976, in two simultaneous outbreaks: one in Nzara (a town in South Sudan) and the other in Yambuku (Democratic Republic of the Congo), a village near the Ebola River from which the disease takes its name. EVD outbreaks occur intermittently in tropical regions of sub-Saharan Africa. From 1976 to 2012, the World Health Organization reports 24 outbreaks involving 2,387 cases with 1,590 deaths. The largest outbreak to date was the epidemic in Guinea (Conacry) and other parts of West Africa, which occurred from December 2013 to January 2016, with 28,646 cases and 11,323 deaths It was declared no longer an emergency on 29 March 2016. Other outbreaks in Africa began in the Democratic Republic of the Congo in May 2017, and 2018. In July 2019, the World Health Organization declared the Congo Ebola outbreak a world health emergency." ("Ebola", Wikipedia)

\section{- Yellow Fever}

- An estimated $90 \%$ of yellow fever infections occur on the African continent. In 2016, a large outbreak originated in Angola and spread to neighboring countries before being contained by a massive vaccination campaign. In March and April 2016, 11 imported cases of the Angola genotype in unvaccinated Chinese nationals were reported in China, the first appearance of the disease in Asia in recorded history.

- Phylogenetic analysis has identified seven genotypes of yellow fever viruses, and they are assumed to be differently adapted to humans and to the vector A. aegypti. Five genotypes (Angola, Central/East Africa, East Africa, West Africa I, and West Africa II) occur only in Africa. West Africa genotype I is found in Nigeria and the surrounding region. West Africa genotype I appears to be especially infectious, as it is often associated with major outbreaks. The three genotypes found outside of Nigeria and Angola occur in areas where outbreaks are rare. Two outbreaks, in Kenya (1992-1993) and Sudan (2003 and 2005), involved the East African genotype, which had remained undetected in the previous 40 years.("Yellow Fever", Wikipedia)

\section{- Spanish Flu}

- Deadly second wave of late 1918: The second wave began in the second half of August, probably spreading to Boston and Freetown, Sierra Leone, by ships from Brest, where it had likely arrived with American troops or French recruits for naval training. From the Boston Navy Yard and Camp Devens (later renamed Fort Devens), about 30 miles west of Boston, other U.S. military sites were soon afflicted, as were troops being transported to Europe. Helped by troop movements, it spread over the next two months to all of North America, and then to Central and South America, also reaching Brazil and the Caribbean on ships. In July 1918, the Ottoman Empire saw its first cases in some soldiers. From Freetown, the pandemic continued to spread through West Africa along the coast, rivers, and the colonial railways, and from railheads to more remote communities, while South Africa received it in September on ships bringing back members of the South African Native Labour Corps returning from France. From there it spread around southern Africa and beyond the Zambezi, reaching Ethiopia in November. ("Spanish flu", Wikipedia)

\section{- Plague}

- The Black Death (also known as the Pestilence, the Great Mortality or the Plague) was a bubonic plague pandemic occurring in Afro-Eurasia from 1346 to 1353. It is the most fatal pandemic recorded in human history, causing the death of 75-200 million people in Eurasia and North Africa, peaking in Europe from 1347 to 1351. Bubonic plague is caused by the bacterium Yersinia pestis, but it may also cause septicaemic or pneumonic plagues. The Black Death was the beginning of the second plague pandemic. The plague created religious, social and economic upheavals, with profound effects on the course of European history. From Crimea, it was most likely carried by fleas living on the black rats that travelled on Genoese slave ships, spreading through the Mediterranean Basin and reaching (Northern) Africa, Western Asia and the rest of Europe. ("Black Death", Wikipedia) 
○ Third plague pandemic 12-15 million, 1855-1960, Worldwide

\section{- Cholera}

- Fifth cholera pandemic, 1881-1896 Asia, Africa, Europe, South America

- Sixth cholera pandemic 1899-1923, Europe, Asia, Africa, Cholera death 800,000+

- 2001 Nigeria cholera epidemic, 2001, Nigeria, Cholera, about 400+ death

- 2001 South Africa cholera epidemic, 2001, South Africa, Cholera, 139 death

- 2006 Luanda cholera epidemic, 2006, Luanda, Angola, Cholera, 1,200+

- 2007 Ethiopia cholera epidemic, 2007, Ethiopia, Cholera, 684 death

- 2008 Chad cholera epidemic ,2008, Chad 123 death

- 2008-09 Zimbabwean cholera outbreak, 2008-2009, Zimbabwe, 4,293 death

\section{- Onchocerciasis, river blindness}

- Onchocerca originated in Africa and was exported to the Americas by the slave trade, as part of the Columbian exchange that introduced other old world diseases such as yellow fever into the New World. Findings of a phylogenetic study in the mid-1990s are consistent with an introduction to the New World in this manner. DNA American strains are identical to savannah strains in Western Africa.

- About 15.5 million people are infected with river blindness. Approximately 0.8 million have some amount of loss of vision from the infection. Most infections occur in sub-Saharan Africa. In 1915, the physician Rodolfo Robles first linked the worm to eye disease. It is listed by the World Health Organization (WHO) as a neglected tropical disease . (wikipedia).

- Various control programs aim to stop onchocerciasis from being a public health problem. The first was the Onchocerciasis Control Programme (OCP), which was launched in 1974, and at its peak, covered 30 million people in 11 countries. Through the use of larvicide spraying of fast-flowing rivers to control black fly populations, and from 1988 onwards, the use of ivermectin to treat infected people, the OCP eliminated onchocerciasis as a public health problem. No vaccine to prevent onchocerciasis infection in humans is available.

- No African country has so far verified elimination of onchocerciasis, but treatment has stopped in some areas (e.g. Nigeria), following epidemiological and entomological assessments that indicated that no ongoing transmission could be detected. In 2015, WHO facilitated the launch of an elimination program in Yemen which was subsequently put on hold due to conflict.

- Uganda's government, working with the Carter Center river blindness program since 1996, switched strategies for distribution of Mectizan, the major drug for treatment of river blindness. The male-dominated volunteer distribution system had failed to take advantage of traditional kinship structures and roles. The program switched in 2014 from village health teams to community distributors, primarily selecting women with the goal of assuring that everyone in the circle of their family and friends received river blindness information and Mectizan. ("Onchocerciasis, river blindness", wikipedia)

- Elimination of human onchocerciasis would make a meaningful contribution to Sustainable Development Goal (SDG) 3.3, which includes a call to end the epidemic of neglected tropical diseases (NTDs) by 2030 (Elimination of human onchocerciasis: progress report, 2019-2020, WHO, 2020).

\section{- Polio}

- Africa: Polio vaccination in Egypt

- In 2003 in northern Nigeria - a country which at that time was considered provisionally polio free - a fatwa was issued declaring that the polio vaccine was designed to render children sterile. Subsequently, polio reappeared in Nigeria and spread from there to several other countries. In 2013, nine health workers administering polio vaccine were targeted and killed by gunmen on motorcycles in Kano, but this was the only attack. Local traditional and 
religious leaders and polio survivors worked to revive the campaign, and Nigeria was removed from the polio-endemic list in September 2015 after more than a year without any cases, only to be restored to the list in 2016 when two cases were detected.

- In 2013 the Center for Disease Control received reports of 183 cases of polio in Somalia, 14 in Kenya and 8 cases in the Somali Region of Ethiopia, but Africa had no confirmed cases of wild poliovirus (WPV) since 2016.[141] Cases of circulating vaccine-derived poliovirus type 2 continue to appear in several countries.

- On 25 August 2020, the Africa Regional Certification Commission declared Africa free from wild polio ("Polio", Wikipedia)

\section{Appendix 2}

\section{(2) Chronic of epidemics in Africa ("Liste of epidemics"s, Wikipedia)}

- 1896-1906 Congo Basin African trypanosomiasis epidemic, 1896-1906, Congo Basin, African trypanosomiasis, 500,000 death

- 1900-1920 Uganda African trypanosomiasis epidemic, 1900-1920, Uganda, African trypanosomiasis , 200,000-300,000 death

- 1996 West Africa meningitus epidemic, 1996, West Africa, Meningitis , 10,000 death

- 2002-04 SARS outbreak, 2002-2004, Worldwide, Severe acute respiratory syndrome / SARS , 774 death

- 2003 Algeria plague outbreak, 2003 Algeria, Bubonic plague ,1 (18 cases)

- 2003-2019 Asia and Egypt Avian influenza epidemic, 2003-2019, Southeast Asia and Egypt, Influenza A virus subtype H5N1, 455 death

- 2006 Ituri Province plague epidemic, 2006, Ituri Province, Democratic Republic of the Congo, Bubonic plague, 61 death

- 2006-07 East Africa Rift Valley fever outbreak, 2006-2007, East Africa Rift Valley fever, 394 death

- Mweka ebola epidemic, 2007, Democratic Republic of the Congo, 187 death

- 2007 Uganda ebola outbreak, 2007, Uganda, Ebola, 37 death

- 2008 Madagascar plague outbreak, 2008, Madagascar, Bubonic plague, 18+

- 2009-10 West African meningitis outbreak 2009-2010, West Africa, Meningitis 1,100 death

- 2009 swine flu pandemic, 2009-2010, Worldwide, Influenza A virus subtype H1N1, Lab confirmed deaths: 18,449 (reported to the WHO), Estimated death toll: 284,000 (possible range 151,700-575,400)

- 2012 yellow fever outbreak in Darfur, Sudan, 2012, Darfur, Sudan, Yellow fever 171 death

- 2012 Middle East respiratory syndrome coronavirus outbreak, 2012, Worldwide Middle East respiratory syndrome / MERS-CoV, 936 death (as of 1 February 2021)

- Western African Ebola virus epidemic, 2013-2016, Worldwide, primarily concentrated in Guinea, Liberia, Sierra Leone, Ebola Ebola virus virion, 11,323+death

- 2014 Madagascar plague outbreak, 2014-2017, Madagascar, Bubonic plague, 292 deeath 
- 2015-16 Zika virus epidemic, 2015-2016, Worldwide, Zika virus, 53 death

- 2016 Angola and DR Congo yellow fever outbreak, 2016, Angola and DR Congo Yellow fever, 498 (377 in Angola, 121 in Congo)

- 2016-2021 Yemen cholera outbreak, 2016-present, Yemen, Cholera, 3,886 (as of 30 November 2019)

- Kivu Ebola epidemic 2018-2020, Democratic Republic of the Congo and Uganda Ebola 2,280 death

- 2019 measles outbreak in the Democratic Republic of the Congo, 2019-2020, Democratic Republic of the Congo, Measles, 7,018+ death

- 2019 Nigeria lassa fever epidemic 2019-present, Nigeria Lassa fever 246 (as of January 2021)

- 2020 Democratic Republic of the Congo Ebola outbreak, 2020, Democratic Republic of the Congo Ebola 55 death

- 2020 Nigeria yellow fever epidemic 2020-present, Nigeria, Yellow Fever, 296 (as of 31 December 2020) 


\section{Annotated Bibliography}

Afolabi, Muhammed O. et al (2020): Lessons from the Ebola epidemics and their applications for COVID-19 pandemic response in sub-Saharan Africa. Bioethics, Volume21, Issue1, March 2021, Pages 25-30 ------- Abstract: COVID-19, caused by a novel coronavirus named SARS-CoV-2, was identified in December 2019, in Wuhan, China. It was first confirmed in sub-Saharan Africa in Nigeria on 27 February 2020 and has since spread quickly to all sub-Saharan African countries, causing more than 111,309 confirmed cases and 2,498 deaths as of 03 June 2020. The lessons learned during the recent Ebola virus disease (EVD) outbreaks in some sub-Saharan African countries were expected to shape and influence the region's responses to COVID-19 pandemic. However, some of the challenges associated with the management of the EVD outbreaks persist and create obstacles for the effective management of the COVID19 pandemic. This article describes the commonalities between the EVD epidemics and COVID-19 pandemic, with a view to draw on lessons learned to effectively tackle the ongoing pandemic. Key successes, failures and lessons learned from previous EVD outbreaks are discussed. Recommendations on how these lessons can be translated to strengthen the COVID-19 response in sub-Saharan Africa are provided.

Arthi, Vellore \& John Parman (2021): Disease, downturns, and wellbeing: Economic history and the long-run impacts of COVID-19. Explorations in Economic History, Volume 79, January 2021, 101381. ----- How might COVID-19 affect human capital and wellbeing in the long run? The COVID-19 pandemic has already imposed a heavy human cost-taken together, this public health crisis and its attendant economic downturn appear poised to dwarf the scope, scale, and disruptiveness of most modern pandemics. What evidence we do have about other modern pandemics is largely limited to short-run impacts. Consequently, recent experience can do little to help us anticipate and respond to COVID-19's potential long-run impact on individuals over decades and even generations. History, however, offers a solution. Historical crises offer closer analogues to COVID-19 in each of its key dimensions-as a global pandemic, as a global recession - and offer the runway necessary to study the life-course and intergenerational outcomes. In this paper, we review the evidence on the long-run effects on health, labor, and human capital of both historical pandemics (with a focus on the 1918 Influenza Pandemic) and historical recessions (with a focus on the Great Depression). We conclude by discussing how past crises can inform our approach to COVID-19-helping tell us what to look for, what to prepare for, and what data we ought to collect now.

Babaniyi, Peter Mwaba et al (2015): Risk Assessment for Yellow Fever in Western and North-Western Provinces of Zambia. J Glob Infect Dis. 2015 Jan-Mar; 7(1): 11-17. doi: 10.4103/0974-777X.150884: 10.4103/0974-777X.150884 ----- North-Western and Western provinces of Zambia were reclassified as low-risk areas for yellow fever $(Y F)$. However, the current potential for YF transmission in these areas is unclear. A cross sectional study was conducted in North-Western and Western provinces of Zambia. Out of the 3625 respondents who participated in the survey, $46.7 \%$ were males and $9.4 \%$ were aged less than 5 years. Overall, $58.1 \%$ of the participants slept under an impregnated insecticide-treated net and 20.6\% reported indoor residual spraying of insecticides. A total of 616 (17.0\%) samples were presumptive $Y F$ positive. The prevalence for $Y F$ was $0.3 \%$ for long-term infection and $0.2 \%$ for recent $Y F$ infection. None of the $Y F$ confirmed cases had received $Y F$ vaccine. Prevalence rates for other flaviviruses were 149 (4.1\%) for Dengue, 370 (10.2\%) for West Nile and 217 (6.0\%) for Zika. There is evidence of past and recent infection of $Y F$ in both provinces. Hence, they are at a low risk for YF infection. Yellow fever vaccination should be included in the EPI program in the two provinces and strengthen surveillance with laboratory confirmation.

BBC news Afrique (n.A.) (2020b): Coronavirus: cinq épidémies qui ont contribué à changer le cours de l'histoire. 28 mars 2020 (no author given, in French) ---------- L'épidémie de coronavirus est en train de changer radicalement la façon dont des millions de personnes dans le monde vivent. Nombre de ces changements seront temporaires. Mais les maladies ont eu, tout au long de l'histoire, d'énormes effets à long terme : de la chute des dynasties, à la montée du colonialisme et même au refroidissement du climat. (1) La peste noire du 14e siècle et l'essor de l'Europe occidentale. (2) Décès dus à la variole en Amérique et changement climatique. (3) Fièvre jaune et révolte d'Haïti contre la France. (4) Peste bovine africaine et expansion coloniale en Afrique.

Beach, Brian \& Karen Clay \& Martin H. Saavedra (2020): The 1918 Influenza Pandemic and its Lessons for COVID-19. Working Paper 27673, NBER, Nat. Bureau of Economic Research, Cambridge, MA, August 2020 ------- The 1918 Influenza Pandemic and its Lessons for COVID19Brian Beach, Karen Clay, and Martin H. SaavedraNBER Working Paper No. 27673August 2020JEL No. IIO,J10,J24,NOABSTRACTThis article reviews the global health and economic consequences of the 1918 influenza pandemic, with a particular focus on topics that have seen a renewed interest because of COVID- 
19. We beginby providing an overview of key contextual and epidemiological details as well as the data that areavailable to researchers. We then examine the effects on mortality, fertility, and the economy in theshort and medium run. The role of nonpharmaceutical interventions in shaping those outcomes is discussedthroughout. We then examine longer-lasting health consequences and their impact on human capitalaccumulation and socioeconomic status. Throughout the paper we highlight important areas for futurework

Blanton, R. E. et al (2020): African Resources and the Promise of Resilience against COVID-19. Am J Trop Med Hyg. 2020 Aug; 103(2): 539-541. ------------ The COVID-19 pandemic has been slow to arrive in the world's poorest countries, especially in Africa. There are good reasons to believe that the consequences for the continent could be worse than anywhere else.1-3 The weaknesses of some governments, healthcare systems, and economies, plus armed conflict, are factors that the virus can and will exploit. A recent British Broadcasting Corporation article noted that there are 10 African countries that have no ventilators, nine have $<1$ per 1 million people, and most of the others have too few to serve their populations in an outbreak of U.S. proportions. 2 African countries need help but are not all helpless. To adequately preview the impact of COVID-19 on the continent, however, both weaknesses and strengths must be considered. The Africa of 2020 is not the Africa of 1960 or even 2014. Africa is a continent of 54 countries, with a range of climatic, cultural, demographic, and economic conditions that contrast them with more developed regions and with each other (Table 1). The country-to-country effects of COVID-19 could be quite different, and there are resources that may help produce better than expected outcomes. "... Benin, Burkina Faso, Cameroon, Ghana, Nigeria, Senegal, and Togo obtained large loans from the World Bank to establish the African Centers of Excellence Project. Some of these centers have been in the forefront of governmental response to outbreaks like Lassa fever, monkeypox, yellow fever, and, presently, COVID-19."

Booysen, F. le R. et al (2002): The Socio-Economic Impact of HIV/AIDS on Households in South Africa: Pilot Study in Welkom and Qwaqwa, Free State Province. University of the Free State Centre for Health Systems Research \& Development, May 2002 ---- Poverty in combination with the HIV/AIDS epidemic seems to represent a major threat to the livelihood of households. Affected households have been shown to be poorer than non-affected households, with poverty being relatively more endemic among affected households. The single most important predictor of poverty status is lack of access to medical aid. In addition, there is some evidence that households affected by death and/or by illness were more likely to be poor, as were households that share fewer years of schooling between its members, that having a smaller number of employed members, that are smaller, that are headed by females, that reside in rural areas, and that are in the affected as opposed to the non-affected group

Bukachi, Salome A (2007): Socio-economic and cultural impacts of human African trypanosomiasis and coping strategies of households in the Busoga Focus (Kenya). Univ. of Nairobi Research Archiv ---------- This study was designed to investigate the socio-economic and cultural impacts of Human African Trypanosimiasis (HAT) and the coping strategies of households in the Busoga focus. Fieldwork for the study was conducted in Busia, Teso and Bunqoma districts of western Kenya, and Busia and Teso districts of southeast Uganda between January 2004 and June 2005. The main assumptions that guided the study were: health-seeking behaviour (HSB) perpetuates the impacts of HAT on affected individuals and households; HAT disrupts the social functioning of households; and HAT affects the economic base of affected households. Data was obtained through: review of hospital records; structured interviews; key informant interviews; in-depth interviews and focus group dlscusslona.Purposive sampling was used ; to obtain the sample size of 481 from b0tt\}.,HAT and non HAT respondents. The quantitative data obtained through structured interviews was analyzed using descriptive statistics and Xlll presented in the form of frequency and", percentage tables. On the other hand, the qualitative data, obtained through review-of hospital records, key informant interviews, indepth interviews and focus group discussions, was analyzed according to emerging themes using a grounded theory approach and presented in the form of case studies, excerpts and quotes. The main findings of this study indicate that delayed diagnosis of HAT led to severe somatic effects on the patients. The findings also reveal that the mental effects of HAT are pronounced among young patients who subsequeptly face diff'iculties fitting back into the community. Households affected by HAT experience increased financial burden as a result of seeking treatment from much different health service providers. The median time lag for starting HAT treatment was between three and four months and much of this time lag is attributable to the health service provider's failure to diagnose HAT. The disease was also sometimes erroneously attributed to HIV/AIDS or witchcraft, causing patients to be stigmatized, delay seeking treatment or to seek treatment from wrong sources. The findings also show that HAT disrupts the normal functioning of affected households. This is manifest through conflicts within marriages, families and the community and reversal of roles, which increased the burden and responsibilities of women and children. On the socio-economic front, the study reveals that HAT impoverishes households through reallocation of household resources to meet the increased financial expenses for seeking treatment and care. Other economic impacts, were school drop-outs, school absenteeism, -" reduced productivity and increased 
funeral and burial expenses. . - This study therefore recommends the in-sti,jutinq' of continuous, concerted inter-border $r$.: measures to reduce the incidences of HAT. In line with this, it is necessary to put in place strategies for effective case finding of HAT at an early stage of HAT. This can be achieved by building the capacity of primary health care personnel to diagnose HAT and to increase $\sim$. their awareness about the same. Similarly, people at risk of HAT should be empowered with relevant information to help them recognize the symptoms of the disease early. Finally the I study recommends the establishment of strategies that would assist HAT patients to be integrated back into the community. This study contributes rich information on the socioeconomic and cultural impacts of HAT that can be used by policy makers and programme implementersto make informed decisions that will help abate the impacts of HAT, as well as give HAT the attention and priority it deserves, considerinq that it is one of the neglected diseases. Additionally, this study reveals that diseases like HAT are an important chain in the cycle of poverty.

Burke, J. (1971): Historique de la lutte contre la maladie du sommeil au Congo. Ann Soc Belg Méd Trop, 1971,51,4-5,465-477 ------ 1885-1904. L'histoire obscure : A la fin du 1 ge siècle et même au cours des premières décennies du 20e siècle, nous ne possédons que relativement peu de renseignements sur l'évolution de la maladie du sommeil en Afrique en général et au Congo en particulier. C'est la période que Buxton appelle 1'« histoire obscure» de la trypanosomiase. Et pourtant, c'est au cours de cette période que se situe l'extension géographique de la maladie, laquelle débuta probablement vers 1885 par une première épidémie qui fut suivie par une seconde vers 1920 et qui ne se stabilisera qu'en 1940 lorsque tout l'ouest et le centre de l'Afrique seront envahis. L'origine de la première épidémie se situe probablement quelque part au confluent du fleuve Congo et de l'Ubangi, d'où elle s'étend rapidement vers le Nord en suivant la rivière Sanga et vers l'Ouest envahissant l'actuelle République populaire du Congo, l'ancien royaume de Loango et le Bas-Congo. En 1887, la maladie est endémique sur le Stanley Pool. Ensuite, l'épidémie s'étend vers le Nord-Est en suivant les eaux du fleuve Congo, de l'Ubangi et du Bomu, pour atteindre le lac Albert en 1888. Peu de détails sont connus sur ce qui se passe à l'intérieur du bassin du Congo. On peut raisonnablement admettre que la maladie ait suivi le cours des innombrables rivières pour faire son apparition ou sa réapparition un peu partout. En 1889 éclate en Uganda autour de Busoga la plus terrible épidémie de trypanosomiase dont on a fait état. Il est parfois admis avec Scott que cette première épidémie pourrait bien avoir trouvé son origine dans les caravanes de Stanley qui, en 1887, quitta les rives du Lualaba pour voler au secours d'Emin Pasha. Ses soldats et porteurs s'établirent en effet avec femme et enfants dans la région de Busoga.

Bwire, Godfrey et al (2017): Epidemiology of cholera outbreaks and socio-economic characteristics of the communities in the fishing villages of Uganda: 2011-2015. PLOS, Published online: March 13, 2017 ----- The communities in fishing villages in the Great Lakes Region of Africa and particularly in Uganda experience recurrent cholera outbreaks that lead to considerable mortality and morbidity. We evaluated cholera epidemiology and population characteristics in the fishing villages of Uganda to better target prevention and control interventions of cholera and contribute to its elimination from those communities. We conducted a prospective study between 2011-15 in fishing villages in Uganda. We collected, reviewed and documented epidemiological and socioeconomic data for 10 cholera outbreaks that occurred in fishing communities located along the African Great Lakes and River Nile in Uganda. These outbreaks caused 1,827 suspected cholera cases and 43 deaths, with a Case-Fatality Ratio (CFR) of 2.4\%. Though the communities in the fishing villages make up only 5-10\% of the Ugandan population, they bear the biggest burden of cholera contributing $58 \%$ and $55 \%$ of all reported cases and deaths in Uganda during the study period. The CFR was significantly higher among males than females (3.2\% vs. $1.3 \%, p=0.02)$. The outbreaks were seasonal with most cases occurring during the months of April-May. Male children under age of 5 years, and 5-9 years had increased risk. Cholera was endemic in some villages with well-defined "hotspots". Practices predisposing communities to cholera outbreaks included: the use of contaminated lake water, poor sanitation and hygiene. Additional factors were: ignorance, illiteracy, and poverty. Cholera outbreaks were a major cause of morbidity and mortality among the fishing communities in Uganda. In addition to improvements in water, sanitation, and hygiene, oral cholera vaccines could play an important role in the prevention and control of these outbreaks, particularly when targeted to high-risk areas and populations. Promotion and facilitation of access to social services including education and reduction in poverty should contribute to cholera prevention, control and elimination in these communities. - Cholera, though a preventable and treatable disease, remains a major cause of morbidity and mortality in the Great Lakes Region of Africa, including Uganda. The communities in the fishing villages constitute 5-10\% of the total Ugandan population. Most fishing villages are located along Lakes Victoria, Albert and Edward and the River Nile. During the study period, 2011-2015 these villages were responsible for over 50\% of the reported annual cholera cases and deaths in Uganda. The CFR was significantly higher among males than females $(3.2 \% \mathrm{vs} .1 .3 \%, p=0.02)$. Our study is the first to systematically describe the epidemiology of these outbreaks and socioeconomic characteristics of communities in the fishing villages in Uganda. Our study found that persons in the fishing villages were at increased risk of cholera outbreaks due to poor access to safe water, sanitation, and hygiene. Furthermore, the villages had similar population characteristics such as illiteracy, ignorance regarding cholera 
transmission, poverty and constant population migration. In addition to improvements in water, sanitation, and hygiene, complementary use of oral cholera vaccines could play an important role, particularly when targeted to high-risk areas and populations. As a long term strategy, improvements in education and reduction in poverty should contribute to cholera prevention, control and elimination in the fishing villages and Uganda as whole.

Caramel, Laurence (2021): L'Afrique face au Covid-19 - la peur du scénario indien. Le Monde (Paris), 30 May 2021 --- La présidence de l'Union africaine réunira les ministres de la santé samedi 8 mai afin de sonner l'alerte. Il s'agit d'appeler à la mobilisation pour mettre le continent à l'abri d'un scénario à l'indienne. « Nous regardons avec stupéfaction ce qui est en train de se passer en Inde. Cela peut arriver n'importe où. Nous devons nous préparer et surtout ne pas baisser la garde », a averti jeudi 29 avril le docteur John Nkengasong, directeur du Centre africain de prévention et de contrôle des maladies (Africa $\mathrm{CDC})$. Les difficultés indiennes ont par ailleurs des répercussions importantes sur les campagnes de vaccination puisque le Serum Institute of India, qui fabrique les vaccins AstraZeneca pour l'initiative de solidarité internationale Covax, a cessé d'exporter depuis plusieurs semaines afin de répondre à la demande domestique. Or, presque tous les pays africains comptent sur Covax pour commencer à immuniser leur population. Avec les autres vaccins - Sinopharm, Spoutnik V et Johnson \& Johnson - 17 millions de doses seulement ont jusqu'à présent été administrées en Afrique, dont 8,9 millions au Maroc. Face aux difficultés logistiques dans un pays aussi grand que l'Europe de l'Ouest et à la réticence des populations, le gouvernement a fait le constat qu'il ne parviendrait pas à administrer ces doses avant leur date d'expiration mi-juin. Les doses restituées vont être redistribuées dans les prochaines semaines à quatre pays : le Ghana, la République centrafricaine, le Sénégal et le Togo.

Çavdaroğlu, Sude et al (2021): The spread of . Yellow fever amidst the COVID-19 pandemic in Africa and the ongoing efforts to mitigate it. J Med Virol, . 2021 Apr 19. ----------- No abstract available

Chauhan, Ravendra P. et al (2020): Systematic Review of Important Viral Diseases in Africa in Light of the 'One Health' Concept. Pathogens, 2020, 9(4), 301; , Published: 20 April 2020 ------- Emerging and re-emerging viral diseases are of great public health concern. The recent emergence of Severe Acute Respiratory Syndrome (SARS) related coronavirus (SARS-CoV-2) in December 2019 in China, which causes COVID-19 disease in humans, and its current spread to several countries, leading to the first pandemic in history to be caused by a coronavirus, highlights the significance of zoonotic viral diseases. Rift Valley fever, rabies, West Nile, chikungunya, dengue, yellow fever, CrimeanCongo hemorrhagic fever, Ebola, and influenza viruses among many other viruses have been reported from different African countries. The paucity of information, lack of knowledge, limited resources, and climate change, coupled with cultural traditions make the African continent a hotspot for vector-borne and zoonotic viral diseases, which may spread globally. Currently, there is no information available on the status of virus diseases in Africa. This systematic review highlights the available information about viral diseases, including zoonotic and vector-borne diseases, reported in Africa. The findings will help us understand the trend of emerging and re-emerging virus diseases within the African continent. The findings recommend active surveillance of viral diseases and strict implementation of One Health measures in Africa to improve human public health and reduce the possibility of potential pandemics due to zoonotic viruses. - Keywords: Africa; emerging; re-emerging; infectious diseases; pandemic; SARS-CoV-2; COVID-19; virus; zoonosis; vectorborne; avian influenza; influenza A virus; coronaviruses; monkeypox; simian immunodeficiency; rabies; dengue; hemorrhagic fever; Rift Valley fever virus; West Nile virus; Ebola; one health; epidemiology

Chippaux, J.P. \& A. Chippaux (2018): Yellow fever in Africa and the Americas: a historical and epidemiological perspective. J Venom Anim Toxins Incl Trop Dis 24, 20 (2018). ------------ Yellow fever was transported during the slave trade in the 15th and 16th centuries from Africa to the Americas where the virus encountered favorable ecological conditions that allowed creation of a sustainable sylvatic cycle. Despite effective vector control and immunization programs for nearly a century, yellow fever epidemics reemerged in many Latin American countries, particularly Brazil. The emergence or reemergence of vector-borne diseases encompasses many intricate factors. Yellow fever outbreaks occur if at least three conditions are fulfilled: the introduction of the virus into a non-immune human community, presence of competent and anthropophilic vectors and insufficiency of prevention and/or adequate management of the growing outbreak. On the other hand, two weapons are available to constrain yellow fever: vector control and immunization. In contrast, yellow fever is absent from Asia and the Pacific despite the presence of the vector and the susceptibility of human populations to the virus. Based on a review of the global history of yellow fever and its epidemiology, the authors deliver some recommendations for improving the prevention of epidemics.

Chitsamatanga, Bellita Banda \& Wayne Malinga (2021): 'A tale of two paradoxes in response to COVID-19': Public health system and socio-economic implications of the 
pandemic in South Africa and Zimbabwe. Cogent Social Sciences, 2021

Africa's response to the outbreak of infectious diseases has come under scrutiny over the years and the outbreak of COVID-19 has exacerbated the situation. The rapid spread of this virus is causing mayhem and panic within the global domain questioning the readiness of public health systems to deal with a pandemic of this magnitude. This has undoubtedly catapulted the word "COVID-19" as a new buzzword. It is in this context that the paper uses desktop research to delve deeper into understanding South Africa and Zimbabwe's responses to the outbreak of COVID-19. In doing so, the main impetus of the paper is to interrogate the public health system and socio-economic implications of this pandemic on both countries. As part of its findings, the paper noted that both countries are a tale of two paradoxes: one with a middleincome status and the other a low-income status; a key factor in determining the level and effectiveness response strategies to this alarming health crisis. However, despite these economic disparities and differential income status, this pandemic has revealed that both countries have similar deep-rooted problems in their already overburdened public health systems. Moreover, the situation is further catapulted and exacerbated by underlying socio-economic factors such as poverty, unemployment, inequality, slow economic development, inadequate water and sanitation, and food insecurity that have made dealing with this pandemic a huge challenge. The paper concludes that the response and attempts to tackle COVID-19 by South Africa and Zimbabwe heavily rely on their health capacity and favourable socio-economic conditions.

Collins, A.E. \& M.E. Lucas \& M.S. Islam \& L.E. Williams (2007): Socio-economic and environmental origins of cholera epidemics in Mozambique: guidelines for tackling uncertainty in infectious disease prevention and control. Pages 537-549 ---- The origins of cholera incidence in Africa are socio-economic and environmental. Moreover, the nature of Vibrio cholerae transmission and survival presents a persistent risk of cholera. The Infectious Disease Risk Management Program (IDRM) in Mozambique confronted this in one of the recent most cholera-prevalent locations of the world. The first phase of the program suggests that recognizing the complexity of cholera is crucial to its effective management. The potential impacts of integrated and locally monitored cholera risk assessment are reduced uncertainty about the origins of epidemics, improved diarrhoeal disease control, and health security.

Davies, Nicholas et al. (2020): The impact of Coronavirus disease 2019 (COVID-19) on health systems and household resources in Africa and South Asia. MedRxiv., The Preprint Server for Health Science, BMJ Yale, --------- Background: Coronavirus disease 2019 (COVID-19) epidemics strain health systems and households. Health systems in Africa and South Asia may be particularly at risk due to potential high prevalence of risk factors for severe disease, large household sizes and limited healthcare capacity. Methods: We investigated the impact of an unmitigated COVID-19 epidemic on health system resources and costs, and household costs, in Karachi, Delhi, Nairobi, Addis Ababa and Johannesburg. We adapted a dynamic model of SARS-CoV-2 transmission and disease to capture countryspecific demography and contact patterns. The epidemiological model was then integrated into an economic framework that captured city-specific health systems and household resource use. Findings: The cities severely lack intensive care beds, healthcare workers and financial resources to meet demand during an unmitigated COVID-19 epidemic. A highly mitigated COVID-19 epidemic, under optimistic assumptions, may avoid overwhelming hospital bed capacity in some cities, but not critical care capacity. Interpretation: Viable mitigation strategies encompassing a mix of responses need to be established to expand healthcare capacity, reduce peak demand for healthcare resources, minimise progression to critical care and shield those at greatest risk of severe disease. Funding: Bill \& Melinda Gates Foundation, European Commission, National Institute for Health Research, Department for International Development, Wellcome Trust, Royal Society, Research Councils UK. Evidence before this study: We conducted a PubMed search on May 5, 2020, with no language restrictions, for studies published since inception, combining the terms ("cost" OR "economic") AND "covid". Our search yielded 331 articles, only two of which reported estimates of health system costs of COVID-19. The first study estimated resource use and medical costs for COVID-19 in the United States using a static model of COVID 19. The second study estimated the costs of polymerase chain reaction tests in the United States. We found no studies examining the economic implications of COVID-19 in low- or middle-income settings. Added value of this study: This is the first study to use locally collected data in five cities (Karachi, Delhi, Nairobi, Addis Ababa and Johannesburg) to project the healthcare resource and health economic implications of an unmitigated COVID-19 epidemic. Besides the use of local data, our study moves beyond existing work to (i) consider the capacity of health systems in key cities to cope with this demand, (ii) consider healthcare staff resources needed, since these fall short of demand by greater margins than hospital beds, and (iii) consider economic costs to health services and households. Implications of all the evidence: Demand for ICU beds and healthcare workers will exceed current capacity by orders of magnitude, but the capacity gap for general hospital beds is narrower. With optimistic assumptions about disease severity, the gap between demand and capacity for general hospital beds can be closed in some, but not all the cities. Efforts to bridge the economic burden of disease to households are needed. 
Dubbink, Jan H. (2020): COVID-19 treatment in sub-Saharan Africa: If the best is not available, the available becomes the best. Travel Med Infect Dis. 2020, September-October; 37: 101878. -----Community transmission of COVID-19 is ongoing in the majority of countries in sub-Saharan Africa (SSA), threatening, as elsewhere, the capacity of national healthcare systems (HCS) in low-and middle-income countries (LMIC). The biggest worry is the lack of health care workers $(H C W)$ and health care infrastructure If the richest countries struggle, what can be done if LMIC, such as Sierra Leone, which serves as an example in the following, are hit hard by the current exponential increase in cases?

Folayan, Coker M. et al (2020): Things must not fall apart: the ripple effects of the COVID-19 pandemic on children in sub-Saharan Africa. Pediatr Res. 2020 Sep 24. ---------- Zero to 19 year-old children in sub-Saharan Africa bear a disproportionate proportion of the global burden of communicable and non-communicable diseases. Significant public health gains have been made in the fight against these diseases, however, factors such as underequipped health systems, disease outbreaks, conflict, and political instability continue to challenge prevention and control. The novel coronavirus disease (COVID-19) pandemic caused by severe acute respiratory syndrome coronavirus 2 (SARS-CoV-2) introduces new challenges to public health programs in sub-Saharan Africa. Of particular concern are programs targeting major conditions among children, such as undernutrition, vaccine-preventable pneumonia and diarrhea, malaria, tuberculosis, HIV, and sickle cell disease. This article focuses on the impact of the COVID-19 pandemic on child health in sub-Saharan Africa. We review the epidemiology of major pediatric diseases and, referencing modeling projections, discuss the short- and long-term impact of the pandemic on major disease control. We deliberate on potential complications of SARS-CoV-2 co-infections/co-morbidities and identify critical social and ethical issues. Furthermore, we highlight the paucity of COVID-19 data and clinical trials in this region and the lack of child participants in ongoing studies. Lastly, approaches and interventions to mitigate the pandemic's impact on child health outcomes are discussed. IMPACT: Children in sub-Saharan Africa bear a disproportionate burden of communicable and non-communicable diseases globally; this remains true even as the COVID-19 pandemic persists. Amidst the fast-expanding COVID-19 literature, there is little comprehensive coverage of the pandemic's indirect impact on child health in subSaharan Africa. This article comprehensively outlines the threat that the pandemic poses to major disease prevention and control for children in sub-Saharan Africa. It discusses the potential impact of SARS-CoV-2 co-infections/co-morbidities, highlights research gaps, and advocates for data and action to mitigate the ripple effects of the pandemic on this population.

Gao, J., et al. (2020). Human African trypanosomiasis: The current situation in endemic regions and the risks for non-endemic regions from imported cases. Parasitology, 147(9), 922-931. doi:10.1017/S0031182020000645 ---- Human African trypanosomiasis (HAT) is caused by Trypanosoma brucei gambiense and Trypanosoma brucei rhodesiense and caused devastating epidemics during the 20th century. Due to effective control programs implemented in the last two decades, the number of reported cases has fallen to a historically low level. Although fewer than 977 cases were reported in 2018 in endemic countries, HAT is still a public health problem in endemic regions until it is completely eliminated. In addition, almost 150 confirmed HAT cases were reported in non-endemic countries in the last three decades. The majority of non-endemic HAT cases were reported in Europe, USA and South Africa, due to historical alliances, economic links or geographic proximity to disease-endemic countries. Furthermore, with the implementation of the 'Belt and Road' project, sporadic imported HAT cases have been reported in China as a warning sign of tropical diseases prevention. In this paper, we explore and interpret the data on HAT incidence and find no positive correlation between the number of HAT cases from endemic and nonendemic countries. This data will provide useful information for better understanding the imported cases of HAT globally in the post-elimination phase.

Gillespie, Stuart (2008): Poverty, Food Insecurity, HIV Vulnerability and the Impacts of AIDS in sub-Saharan Africa. IDS-Bulletin, volume 39, issue 5 (2008), DOI: $10.1111 / \mathrm{j} .1759-5436.2008 . t \mathrm{~b} 00490 . \mathrm{x}$----- Throughout this decade, the prevailing narrative onthe links between socioeconomic status and HIVportrays poor individuals and households as beingmore vulnerable to HIV infection, land least able tocope with the ensuing impacts of AIDS-relateddisease and death. While early stages of the epidemicin the 1980s and early 1990s were driven by 'mobilemen with money', AIDS is now conventionallyperceived as a disease of poverty. But is this toosimplistic? This brief overview aims to review the currentevidence on the upstream and downstream linksbetween poverty, food insecurity, HIV vulnerabilityand the impacts of AIDS. The first section focuses onthe upstream - that is, whether, and through whatpathways, poverty puts people at greater risk ofbeing exposed to the virus. This is followed by anexamination of what is known about thedownstream (or post-infection) side - how AIDSrelated disease, and premature mortality exacerbateor precipitate poverty.

Hagan, John Elvis et al (2020): Africa's COVID-19 Situation in Focusand Recent Happenings: A MiniReview. Front. Public Health, 17 December 2020 -------- Given that COVID-19 (SARS-CoV-2) has crept into Africa, a major public health crisisor threat continues to linger on 
the continent. Many local governments and variousstakeholders have stepped up efforts for early detection and management of COVID-19.This mini review highlights the current trend in Africa, history and general epidemiologicalinformation on the virus. Current ongoing efforts (e.g., improving testing capacity) andsome effective ways (e.g., intensified surveillance, quickdetection, contact tracing, isolation measures [e.g., quarantine], and social distancing) of preventing and managing COVID-19 in Africa are described. The review concludes by emphasizing the need forpublic health infrastructure development (e.g., laboratories, infectious disease centers, regional hospitals) and human capacity building for combating COVID-19 and potentialfuture outbreaks. Additionally, regular public health educational campaigns are urgentlyrequired. Future epidemiological studies to ascertain case fatality and mortality trendsacross the continent for policy directions are necessary.

Josephson, Anna \& Kilic, Talip \& Michler, Jeffrey D. (2020): Socioeconomic Impacts of COVID-19 in Four African Countries. Policy Research Working Paper;No. 9466. World Bank, Washington, DC. (C) World Bank. ----- The coronavirus disease 2019 (COVID-19) and the attempts to limit its spread have resulted in profound economic impacts, and a significant contraction in the global economy is expected. This paper provides some of the first evidence on the socioeconomic impacts of and responses to the pandemic among households and individuals in Sub-Saharan Africa. To do so, reducedform econometric methods are applied to longitudinal household survey data from Ethiopia, Malawi, Nigeria, and Uganda -- originating from the pre-COVID-19 face-to-face household surveys and from the novel phone surveys that are being implemented during the pandemic. The headline findings are fourfold. First, although false beliefs about COVID-19 remain prevalent, government action to limit the spread of the disease is associated with greater individual knowledge of the disease and increased uptake of precautionary measures. Second, 256 million individuals -- 77 percent of the population in the four countries -- are estimated to live in households that have lost income due to the pandemic. Third, attempts to cope with this loss are exacerbated by the inability to access medicine and staple foods among 20 to 25 percent of the households in each country, and food insecurity is disproportionately borne by households that were already impoverished prior to the pandemic. Fourth, student-teacher contact has dropped from a pre-COVID-19 rate of 96 percent to just 17 percent among households with school-age children. These findings can help inform decisions by governments and international organizations on measures to mitigate the effects of the COVID19 pandemic and reveal the need for continued monitoring

Krawczyk-2020: How nonprofits (NGOs) have been affected during pandemic. Auburn University, Office of Communications \& Marketing Expert Answers, 2020 May Many nonprofit organizations went into this emergency without large amounts of reserve funds. And now, the coronavirus pandemic has made their financial situation even more dire. Fundraising events have been cancelled or postponed, and ticket sales are gone. Donors are worried about the economy and, in some cases, have pulled back on giving. Foundations have suffered huge losses to endowments. So, nonprofits are currently struggling to survive financially. Yet at the same time, the needs of those they serve are greater than ever.

Leach, M. \& H. Mac Gregor \& I. Scoones, A. Wilkinson (2021): Post-pandemic transformations: How and why COVID-19 requires us to rethink development. World Development, Volume 138, February 2021, 105233 ----- COVID-19 is proving to be the long awaited 'big one': a pandemic capable of bringing societies and economies to their knees. There is an urgent need to examine how COVID-19 - as a health and development crisis - unfolded the way it did it and to consider possibilities for post-pandemic transformations and for rethinking development more broadly. Drawing on over a decade of research on epidemics, we argue that the origins, unfolding and effects of the COVID-19 pandemic require analysis that addresses both structural political-economic conditions alongside far less ordered, 'unruly' processes reflecting complexity, uncertainty, contingency and context-specificity. This structural-unruly duality in the conditions and processes of pandemic emergence, progression and impact provides a lens to view three key challenge areas. The first is how scientific advice and evidence are used in policy, when conditions are rigidly 'locked in' to established power relations and yet so uncertain. Second is how economies function, with the COVID-19 crisis having revealed the limits of a conventional model of economic growth. The third concerns how new forms of politics can become the basis of reshaped citizen-state relations in confronting a pandemic, such as those around mutual solidarity and care. COVID-19 demonstrates that we face an uncertain future, where anticipation of and resilience to major shocks must become the core problematic of development studies and practice. Where mainstream approaches to development have been top down, rigid and orientated towards narrowly-defined economic goals, post-COVID-19 development must have a radically transformative, egalitarian and inclusive knowledge and politics at its core.

Lyons, Maryinez (1992): The Colonial Disease: A Social History of Sleeping Sickness in Northern Zaire, 1900-1940. Cambridge History of Medicine. New York: Cambridge University Press ------ The Belgians commonly referred to their colonisation of the Congo as a 'civilising mission', and many regarded the introduction of western bio-medicine as a central feature of their 'gift' to 
Africans. By 1930, however, it was clear that some features of their 'civilising mission' were in fact closely connected to the poor health of many of the Congolese. The Europeans had indeed brought scientific enquiry and western bio-medicine; but they had also introduced a harsh, repressive political system which, coupled with a ruthlessly exploitative economic system, led to the introduction of new diseases while already-existing diseases were exacerbated and spread. Tropical, or 'colonial', medicine was a new field at the turn of the century, linked closely both to European expansionism and human trypanosomiasis, or sleeping sickness. In 1901 a devastating epidemic had erupted in Uganda, killing well over 250,000 people.

Machila, Nisbert (2013): Trypanosomiasis, the State and Livelihoods in Eastern Province of Zambia, 1908-1964. researchgate.net --------- Trypanosomiasis was a major problem in Zambia, in particular Eastern Province during the colonial period. For centuries the people of Eastern province of Zambia were subjected to trypanosomiasis. This dissertation examines trypanosomiasis in Eastern Province of Zambia from 1908 to 1964. The dissertation argues that upon the discovery of the disease, the British South African Company expressed fear and great panic and measures had to be taken quickly. It also demonstrates that through the Veterinary Department, B.S.A.Co carried out appropriate measures that were intended to contain and prevent the spread of tsetse flies and trypanosomiasis. The study also argues that the outbreak of the Second World War in 1939 limited the availability of funds for tsetse fly and trypanosomiasis control programmes. This exacerbated the situation. It was not until the end of the Second World War in 1945 that the colonial administration became actively involved in the control of the disease. This study also demonstrates that the people of Eastern Province of Zambia developed traditional survival strategies and ethno-veterinary medicines to cope with trypanosomiasis in their communities. The Africans largely depended on their knowledge of the environment to control trypanosomiasis. The study explores various mechanisms that the people of Eastern province of Zambia employed for survival during outbreaks of the disease. Colonial intervention through the Veterinary and Tsetse Control Departments also became a major source of ethno-veterinary medicine..

Malczycki, Matt (2020): COVID-19-compared to other pandemics-is historic because of world response. Auburn University, Published: May 26, 2020 ---------- What makes COVID19 historic so far is the speed at which the world moved to stop the spread of the disease. Yes, the quarantines and the shutdowns could have saved lives if they had happened sooner, but, in the grand scheme of human history, the global response to COVID-19 set speed records. At just about any other time, we would not have been able to act as thoroughly as we did as quickly as we did. Millions more would have been infected and died without modern information technology and medicine. In the parlance of our times, to some extent we did "flatten the curve," and we did it better than we ever have.

Mwiinde, A.M. \& Simuunza, M. \& Namangala, B. et al. (2017): Estimating the economic and social consequences for patients diagnosed with human African trypanosomiasis in Muchinga, Lusaka and Eastern Provinces of Zambia (2004-2014). Infect Dis Poverty 6, 150 (2017). https://doi.org/10.1186/s40249-017-0363-6 ------ Acute human African trypanosomiasis (rHAT) caused by Trypanosoma brucei rhodesiense is associated with high mortality and is fatal if left untreated. Only a few studies have examined the psychological, social and economic impacts of rHAT. In this study, mixed qualitative and quantitative research methods were used to evaluate the socioeconomic impacts of rHAT in Mambwe, Rufunsa, Mpika and Chama Districts of Zambia.

Montes, Jose et al (2020): How much will poverty rise in Sub-Saharan Africa in 2020 ?. World Bank, Poverty \& Equity Notes, No. 20, May 2020 --------- The ongoing coronavirus pandemic is expected to drastically slow 2020 GDP per capita growth in Sub-Saharan Africa (SSA) by about 5 percentage points compared to pre-pandemic forecasts. This note presents results from an analysis of a comprehensive database of surveys from 45 of 48 SSA countries to examine the effects of the project fall in growth on povertyin the region. An additional 26 million people in SSA, and as much as 58 million, may fall into extreme poverty defined by the international poverty line of US\$1.90 per day in 2011 PPP. The poverty rate for SSA will likely increase more than two percentage points, setting back poverty reduction in the region by about 5 years.

Mulchandani, Ranya et al (2019): A community-level investigation followinga yellow fever virus outbreak in South OmoZone, South-West Ethiopia. Peer J., February 20, 2019 ------ Despite the availability of a highly effective vaccine, yellow fever virus (YFV) remains an important public health problem across Africa and South America due to its high case-fatality rate. This study investigated the historical epidemiology and contemporary entomological and social determinants of a YFV outbreak in South Omo Zone (SOZ), Ethiopia. Study results highlight the potential role vector control could play in mitigating local disease transmission and emphasize the urgent need to strengthen disease surveillance systems and in-country laboratory capacity to facilitate more rapid responses to future YFV outbreaks. 
Musambachime, M. C. (1981). The Social and Economic Effects of Sleeping Sickness in Mweru-Luapula 1906-1922. African Economic History, (10), 151. doi:10.2307/3601298 ---- Human African Trypanosomiasis (HAT), a disease caused by protozoan parasites transmitted by tsetse flies, is an important neglected tropical disease endemic in remote regions of sub-Saharan Africa. Although the determination of the burden of HAT has been based on incidence, mortality and morbidity rates, the true burden of HAT goes beyond these metrics. This study sought to establish the socio-economic burden that households with HAT faced and the coping strategies they employed to deal with the increased burden.

Mutebi, John-Paul \& Alan D.T. Barrett (2020) The epidemiology of yellow fever in Africa (Review). Microbes and Infection, Volume 4, Issue 14, November 2002, pp 1459-1468 ------- Yellow fever $(Y F)$ is still a major public heath problem, particularly in Africa, despite the availability of a very efficacious vaccine. The World Health Organization estimates that there are 200,000 cases of YF annually, including 30,000 deaths, of which over 90\% occur in Africa. In the past 15 years, the number of YF cases has increased tremendously, with most of the YF activity in West Africa. This increase in YF activity is in part due to a breakdown in $Y F$ vaccination and mosquito control programs. Five genotypes of $Y F$ virus have been found in Africa, and each genotype circulates in a distinct geographical region. West Africa genotype I, found in Nigeria and surrounding areas, is associated with frequent epidemics, whereas the three genotypes in East and Central Africa are in regions where YF outbreaks are rare. Other factors, including genetic and behavioral variation among vector species, are also thought to play a role in the epidemiology of $Y F$ in Africa.

Nattrass, Nicoli (2003): The Moral Economy of AIDS in South Africa. Cambridge University Press ------ Relatively few people have access to antiretroviral treatment in South Africa. The government justifies this on grounds of affordability.Nicoli Nattrass argues that the government's view insulates AIDS policy from social discussion and efforts to fund large-scale intervention. Nattrass addresses South Africa's contentious AIDS policy from both an economic and ethical perspective, presenting: * a history of AIDS policy in South Africa * an expert analysis of the macroeconomic impact of AIDS * a delineation of the relationship between AIDS and poverty and the challenges it poses for development, inequality and social solidarity * an investigation into how a programme preventing mother-to-child transmission would be less expensive than having to treat children with AIDS-related illnesses $*$ an exploration of the relationship between AIDS treatment and risky sexual behaviour * an economic and social case for expanded AIDS prevention and treatment intervention. This relevant and accessible work is a valuable resource for readers with an interest in AIDS policy and the social and economic implications of the pandemic.

Ndongko,T. M. (1996): A preliminary study of the socio-economic impact of HIV/AIDS in Africa. Africa Development / Afrique et Développement, CODESRIA, Dakar, Vol. 21, No. 1 (1996), pp. 39-55 ----- L'article présente une étude préliminaire de l'impact socio-économique du Sida/VIH en Afrique. Examinant l"évolution générale de la propagation de la pandémie et son impact sur les différents aspects de la vie économique et sociale, l'auteur démontre que les résponses nationales et locales au niveau des pays africains, bien qu'elles constituent un début, n'en demandent pas moins beaucoup d'attention et de moyens. L'auteur termine son article en suggérant ce qu'il est possible de faire à tous niveaux pour la prise en charge de la pandémie.

Nweze, J. A. \& I. Eke \& E.I. Nweze (2017): HIV/AIDS in sub-Saharan Africa: Current status, challenges and prospects. Asian Pacific Journal of Tropical Disease 7(4):239-256; DOI:10.12980/apjtd.7.2017D6-366 ----- The problem of HIVIAIDS was sort of a fairy tale and mere information till the immunological disorder was scientifically confirmed. Today, HIV/AIDS has continued to be a serious international health concern, and sub-Saharan Africa remains the most affected region. Over 25.6 million persons are currently living with HIV in sub-Saharan Africa. This accounts for two-thirds of the recent overall world HIV infections and more than 70 percent of all AIDSrelated deaths. In 2015, Eastern and Southern Africa had about $7.1 \%$ adult HIV prevalence rate (about 19 million HIV patients), while Western and Central Africa accounted for about 2.2\% (about 6.5 million HIV patients). Few countries now boast of numerous signs of gradual to moderate declines in HIV occurrence. However, HIV prevalence rate has continued to increase in countries like Lesotho (22.7\%), Botswana (22.2\%) and South Africa (19.2\%). The nature, procedure and result of the scourge in this region have been fashioned by a mind-boggling interaction of traditional, behavioural, social and material factors. Even if there are notably strong prevention, treatment and care programmes, too many sexual partners are engaging in risky sexual practices. The aim of this article is to discuss the current trends of HIV/AIDS in sub-Saharan Africa, the factors that might have contributed to high prevalence of the virus in the region, the effect of the HIV/AIDS scourge, the prevention programmes and the way forward. 
Ngalamulume, Kalala (2021): 'Pestilential Emanations', Medical Knowledge, and Stigmatisation in Saint-Louis, Senegal, 1854-1920. eTropic: electronic journal of studies in the Tropics, Vol. 20 No. 1 (2021): Special Issue: Pandemic, Plague, Pestilence and the Tropics ------ Abstract: This article shows how French doctors based in Saint--Louis--du--Sénégal, the capital of colonial Senegal, conceptualised the Senegambian region as a diseased environment and Africans as carriers of infectious agents. It explains how perceptions of the hot tropical climate, combined with outbreaks of epidemic diseases and seasonal allergies, were instrumental in the processes of urban transformation through hygienic measures such as waste removal, the closing of cemeteries, and the imposition of new building codes. The article also shows how the stigmatisation of Africans was implicated in the forced removal of the urban poor - firstly from the city centre, and later from the entire city-island. Colonial medical knowledge in Senegal was initially based on the miasma theory, however, germ theory was adopted in the aftermath of the 1900 yellow fever epidemic. Both theories, in relation with racialism, impacted the urban landscape in Saint-Louis, Senegal.

Ochola, Elizabeth A. \& Diana M. S. Karanja \& Susan J. Elliott (2021): The impact of Neglected Tropical Diseases (NTDs) on health and wellbeing in sub-Saharan Africa (SSA): A case study of Kenya. PLOS Neglected tropical diseases.15(2): e0009131 ----- Neglected Tropical Diseases (NTDs) remain endemic to many regions of sub-Saharan Africa (SSA) left behind by socioeconomic progress. As such, these diseases are markers of extreme poverty and inequity that are propagated by the political, economic, social, and cultural systems that affect health and wellbeing. As countries embrace and work towards achieving the Sustainable Development Goals (SDGs), the needs of such vulnerable populations need to be addressed in local and global arenas. The research uses primary qualitative data collected from five NTD endemic counties of Kenya: interviews key informants $(n=21)$ involved in NTD implementation programs and focus groups $(n=5)$ of affected individuals. Informed by theories of political ecology of health, the research focuses on post-devolution Kenya and identifies the political, economic, social, and cultural factors that propagate NTDs and their effects on health and wellbeing. Our findings indicate that structural factors such as competing political interests, health worker strikes, inadequate budgetary allocations, economic opportunity, marginalization, illiteracy, entrenched cultural norms and practices, poor access to water, sanitation and housing, all serve to propagate NTD transmission and subsequently affect the health and wellbeing of populations. As such, we recommend that post-devolution Kenya ensures local political, economic and socio-cultural structures are equitable, sensitive and responsive to the needs of all people. We also propose poverty alleviation through capacity building and empowerment as a means of tackling NTDs for sustained economic opportunity and productivity at the local and national level.

Olago, Daniel \& Michael Marshall \& Shem O. Wandiga (2007): Climatic, Socio-Economic, and Health Factors Affecting Human Vulnerability to Cholera in the Lake Victoria Basin, East Africa. Ambio, Vol. 36, No. 4 (Jun., 2007), pp. 350-358 --- Cholera epidemics have a recorded history in the eastern Africa region dating to 1836. Cholera is now endemic in the Lake Victoria basin, a region with one of the poorest and fastest growing populations in the world. Analyses of precipitation, temperatures, and hydrological character- istics of selected stations in the Lake Victoria basin show that cholera epidemics are closely associated with El Nino years. Similarly, sustained temperatures high above normal (Tmax) in two consecutive seasons, followed by a slight cooling in the second season, trigger an outbreak of a cholera epidemic. The health and socioeconomic systems that the lake basin communities rely upon are not robust enough to cope with cholera outbreaks, thus rendering them vulnerable to the impact of climate variability and change. Collectively, this report argues that communities living around the Lake Victoria basin are vulnerable to climate-induced cholera that is aggra-vated by the low socioeconomic status and lack of an adequate health care system. In assessing the commu- nities' adaptive capacity, the report concludes that persistent levels of poverty have made these communi-ties vulnerable to cholera epidemics

Oldstone, Michael (2009). Viruses, Plagues, and History: Past, Present and Future. Oxford University Press. --- Viruses, Plagues, \& History not only shows us what viruses are and how they work, but looks at what newer ones such as Ebola and HIV might mean to our future. Even more frightening, Oldstone discusses the influenza virus of 1918 to 1919--which may have killed as many as 50 million people worldwide and certainly helped England, France, and the U.S. defeat Germany in World War I--and wonders if it's due for a return visit. Granted, a book with a chapter titled "Mad Cow Disease and Englishmen: Spongiform Encephalopathies--Virus or Prion Disease?" isn't for everybody, but it's a fascinating for anyone interested in health and wellness and the medical future of our planet.

Ozbay, Gulcin et al (2020): A comparative evaluation between the impact of previous outbreaks and COVID-19 on the tourism industry. International Hospitality Review, Article publication date: 25 January 2021 ------ The main purpose of this study is to make a comparative evaluation of the impacts of previous outbreaks and coronavirus disease 2019 (COVID-19) on 
the tourism industry. COVID-19 appears to have disrupted all memorizations about epidemics ever seen. Nobody has anticipated that the outbreak in late December will spread rapidly across the world, be fatal and turn the world economy upside down. Severe acute respiratory syndrome, Ebola, Middle East respiratory syndrome and others caused limited losses in a limited geography, thus similar behaviors were expected at first in COVID-19. But it was not so. Today, people continue to lose their lives and experience economic difficulties. One of the most important distressed industries is undoubtedly tourism.

Ozili, Peterson K (2020): COVID-19 in Africa: socioeconomic impact, policy response and opportunities. MPRA-WP: 103316 ----- The COVID-19 or coronavirus pandemic which has affected the global economy has also affected the African economy through spillovers to African countries. Many African countries have taken bold quarantine and lockdown measures to control the spread of COVID-19 although this has come at a cost such as the collapse of health systems and a painful economic crisis or recession. A coordinated and bold response by African authorities is needed. First, public funds should be provided to improve the capacity of health systems in African countries. Second, financial support should be provided to individuals, entrepreneurs and corporations to help them cope with the adverse effect of the coronavirus crisis. Third, employers should be granted incentives to preserve employment during the crisis to avoid mass layoff of workers. Finally, the Central bank in African countries should provide liquidity and credit support as well as asset purchase programs to prevent credit and liquidity crunch in domestic financial markets.

Paintsil, Elijah (2020): COVID-19 threatens health systems in sub-Saharan Africa: the eye of the crocodile. J Clin Invest. 2020;130(6):2741-2744, ----- The threat of coronavirus disease 2019 (COVID-19) to health systems in sub-Saharan Africa (SSA) can be compared metaphorically to a lake in Africa infested with a bask of crocodiles and the saying "the eye of the crocodile." In the lake, only the eyes of the crocodile appear on the surface while the rest of the body is submerged in water. In this Viewpoint, the eyes and the body of the crocodile represent the public health preparedness and health systems, respectively, in SSA. SSA has had multiple epidemics, including, in the last 3 decades, HIV and Ebola virus. Interestingly, HIV, Ebola virus, and SARS-CoV-2 are all of zoonotic origin. HIV resulted from cross-species transfer of simian immunodeficiency virus from chimpanzees, found in eastern and central Africa, to humans (1). Ebola virus was discovered in humans during concurrent outbreaks in the Democratic Republic of Congo and the Sudan in 1976 (2, 3). It is believed that bats are the natural hosts of Ebola virus. SARS-CoV-2 also originated from bats found in caves in China. Although HIV and Ebola originated in Africa, SARS-CoV-2 was imported from China. This Viewpoint discusses the potential impact of the COVID19 epidemic on already-fragile health systems in SSA and forecasts lessons likely to be learned from COVID19 in SSA.

Parman, John (2021): Disease, downturns, and wellbeing: Economic history and the long-run impacts of COVID-19. Explorations in Economic History, Volume 79, January 2021, 101381 ------ How might COVID-19 affect human capital and wellbeing in the long run? The COVID-19 pandemic has already imposed a heavy human cost-taken together, this public health crisis and its attendant economic downturn appear poised to dwarf the scope, scale, and disruptiveness of most modern pandemics. What evidence we do have about other modern pandemics is largely limited to short-run impacts. Consequently, recent experience can do little to help us anticipate and respond to COVID-19's potential long-run impact on individuals over decades and even generations. History, however, offers a solution. Historical crises offer closer analogues to COVID-19 in each of its key dimensions - as a global pandemic, as a global recession - and offer the runway necessary to study the life-course and intergenerational outcomes. In this paper, we review the evidence on the long-run effects on health, labor, and human capital of both historical pandemics (with a focus on the 1918 Influenza Pandemic) and historical recessions (with a focus on the Great Depression). We conclude by discussing how past crises can inform our approach to COVID-19-helping tell us what to look for, what to prepare for, and what data we ought to collect now.

Pilling, David (2020): How Africa fought the pandemic, and what coronavirus has taught the world. Financial Times (London), October 23, 2020 ----- Can similar future outbreaks be prevented? The vital lessons of Covid-19 can be learned from African countries' powerful response. Please use the sharing tools found via the share button at the top or side of articles. Copying articles to share with others is a breach of FT.com T\&Cs and Copyright Policy. Email licensing@ft.com to buy additional rights. Subscribers may share up to 10 or 20 articles per month using the gift article service. Genomic analysis would later reveal that almost all infections brought into Africa came not from China but from Europe, what Mr Nkengasong calls an "amphibious attack". It is a reversal of the normal patterns of infectious disease in which Africa is so often the epicentre. This time, the threat was coming from the north. Apart from a handful of countries, such as South Africa and Egypt, there were virtually no intensive care units in a continent of $1.3 b n$ people, although sophisticated equipment would not be the key to managing the pandemic, even in rich countries. HIV has since infected $75 \mathrm{~m}$ people worldwide and killed $32 \mathrm{~m}$, the majority in Africa. Like HIV, 
which spread to humans from monkeys, coronavirus jumped from an animal, in this case a bat. The working theory is that Sars-Cov-2, the virus that causes Covid-19, probably made the leap to people via a mammal, possibly a pangolin butchered at a wet market in the Chinese city of Wuhan. In almost every respect, Africa is at a disadvantage compared with richer continents. Apart from one. Africans know all too much about infectious diseases. While the virus sent Europeans and Americans into panic, many Africans shrugged. They are veterans of hard-knock battles against endemic diseases such as malaria, tuberculosis and cholera, and more recently emerging ones such as Lassa fever and HIV/Aids. Inevitably, the virus pierced Africa's hastily erected defences, spreading to almost 40 countries by March 20. But numbers were relatively low and many countries mounted an aggressive effort to snuff out new infections. Rwanda, was one of the most aggressive. On January 31, 2020 it cancelled flights from China. A week after the first case slipped through the net in March, it suspended international flights altogether, closed its borders and told people to stay indoors. South Africa also took bold steps. On March 23, 2020, before a single Covid-19 death, President Ramaphosa announced a three-week lockdown, one of the strictest in the world. All but essential workers were ordered to stay at home and sales of alcohol were banned. Not all African countries could do likewise. Indeed, there was an argument that western-style lockdowns might do more harm than good. Poor people had to eat. And insisting they stayed in crowded informal settlements was hardly a recipe for social distancing. Some warned that lockdowns were an overreaction. After all, Africa has a very young population, with a median age of 19.4, about half that of Europe. There is little obesity. If societies shut down, then vital programmes, including vaccination campaigns and maternal healthcare, could stop, causing more damage than Covid-19 itself.

Pitlik, Silvio Daniel (2020): COVID-19 Compared to Other Pandemic Diseases. Rambam Maimonides Med J., 2020 Jul; 11(3): e0027. online 2020 Jul 31. --------- Pandemics Originating Mainly in Tropical Areas. Yellow fever epidemics occur mainly in Africa and South America. The disease is transmitted by several species of mosquitoes, mainly by Aedes aegypti. The disease life cycle has two possible scenarios: (1) the sylvatic cycle, where the hosts are various types of animals, primarily monkeys; and (2) the urban cycle, where the reservoir is human beings. Outbreaks occur mainly during the rainy season. Water accumulation, on land or in various objects, facilitates development of vector mosquitos. Other viruses transmitted by Aedes aegypti include dengue virus, Zika virus, and chikungunya virus. - For close to half a century, several Ebola virus outbreaks have occurred in Western and Central Africa. The long-term reservoir of this virus is a species of bats. Due to massive deforestation, there have been episodes of viral spillover to humans and animals, including gorillas and chimpanzees. Subsequently, human-tohuman transmission occurred as the result of close contact with patients or bodies at burial ceremonies, and some convalescing patients continued to transmit the virus for some time after recovery. Due to the high contagiousness of Ebola, many health care workers were also infected. Currently, there is an effective vaccine to prevent Ebola (Table 5) as well as a drug composed of three types of antibodies (Table 6).51

Rutto, Jane J. et al (2013): Socio-Economic and Cultural Determinants of Human African Trypanosomiasis at the Kenya - Uganda Transboundary. PubMed / PLoS Neglected Tropical Diseases 7(4):e2186 / Researchgate, April 2013; DOI: 10.1371/journal.pntd.0002186 ----- Kenya and Uganda have reported different Human African Trypanosomiasis incidences in the past more than three decades, with the latter recording more cases. This cross-sectional study assessed the demographic characteristics, tsetse and trypanosomiasis control practices, socio-economic and cultural risk factors influencing Trypanosoma brucei rhodesiense (T.b.r.) infection in Teso and Busia Districts, Western Kenya and Tororo and Busia Districts, Southeast Uganda. A conceptual framework was postulated to explain interactions of various socio-economic, cultural and tsetse control factors that predispose individuals and populations to HAT. Methods: A cross-sectional household survey was conducted between April and October 2008. Four administrative districts reporting T.b.r and lying adjacent to each other at the international boundary of Kenya and Uganda were purposely selected. Household data collection was carried out in two villages that had experienced HAT and one other village that had no reported HAT case from 1977 to 2008 in each district. A structured questionnaire was administered to 384 randomly selected household heads or their representatives in each country. The percent of respondents giving a specific answer was reported. Secondary data was also obtained on socio-economic and political issues in both countries. Results: Inadequate knowledge on the disease cycle and intervention measures contributed considerable barriers to HAT, and more so in Uganda than in Kenya. Genderassociated socio-cultural practices greatly predisposed individuals to HAT. Pesticides-based crop husbandry in the 1970's reportedly reduced vector population while vegetation of coffee and banana's and livestock husbandry directly increased occurrence of HAT. Livestock husbandry practices in the villages were strong predictors of HAT incidence. The residents in Kenya (6.7\%) applied chemoprophylaxis and chemotherapeutic controls against trypanosomiasis to a larger extent than Uganda (2.1\%). Conclusion: Knowledge on tsetse and its control methods, culture, farming practice, demographic and socio-economic variables explained occurrence of HAT better than landscape features. 
Saeed, Omar et al (2018): Chapter 12 - Psychological and Social Aspects of Zika Virus Disease. In: The Zika Virus Disease - From Origin To Outbreak. 2018, pp. 143-153. Zika virus disease is usually a mild disease among adults that causes a light fever, skin rash, conjunctivitis (red eyes), muscle or joint pain, and general malaise that begins 2-7 days after the bite of an infected mosquito. Only 20\% of the infected people develop symptoms of the disease. However, there is strong suspicion that Zika virus is linked to congenital microcephaly which is a rare condition wherein a baby has unusually a small head and will later have developmental issues as they grow older. As Zika virus disease affects mostly pregnant woman, it has created a high-level of psychological stress among this population. It is quite understandable that even the thought of giving birth to a child with a malformation, regardless of whether the malformation has been caused by Zika virus disease, is certainly a stressful event for a family.

Sardon, Jean-Paul (2020): De la longue histoire des épidémies au Covid-19. Les Analyses de Population \& Avenir, 2020, 10.3917 ------ Human history is marked by epidemic diseases. They have always followed movements, linked to trade or wars. These epidemics, defined as plagues before modern times, could be caused by different diseases (typhoid, smallpox, bubonic or pulmonary plague, yellow fever). Recent acceleration in travel, along with the development of air travel, has increased the speed of spread of new epidemics. However, progress in detecting cases and the speed with which treatments have been implemented most often have made it possible to limit their health consequences. From the plagues of Antiquity to the current Covid-19pandemic, including the Black Death and the Spanish flu, the great past epidemics are reviewed, as well as the number of their victims.

Sharp, Paul M. \& and Beatrice H. Hahn (2011): Origins of HIV and the AIDS Pandemic. Cold Spring Harb Perspect Med., 2011 Sep; 1(1), doi: 10.1101/cshperspect.a006841 ---Acquired immunodeficiency syndrome (AIDS) of humans is caused by two lentiviruses, human immunodeficiency viruses types 1 and 2 (HIV-1 and HIV-2). Here, we describe the origins and evolution of these viruses, and the circumstances that led to the AIDS pandemic. Both HIVs are the result of multiple cross-species transmissions of simian immunodeficiency viruses (SIVs) naturally infecting African primates. Most of these transfers resulted in viruses that spread in humans to only a limited extent. However, one transmission event, involving SIV cpz from chimpanzees in southeastern Cameroon, gave rise to HIV-1 group M-the principal cause of the AIDS pandemic. We discuss how host restriction factors have shaped the emergence of new SIV zoonoses by imposing adaptive hurdles to cross-species transmission and/or secondary spread. We also show that AIDS has likely afflicted chimpanzees long before the emergence of HIV. Tracing the genetic changes that occurred as SIVs crossed from monkeys to apes and from apes to humans provides a new framework to examine the requirements of successful host switches and to gauge future zoonotic risk.

Steverding, D. (2008): The history of African trypanosomiasis. Parasites Vectors 1, 3 (2008). https://doi.org/10.1186/1756-3305-1-3 ----- The prehistory of African trypanosomiasis indicates that the disease may have been an important selective factor in the evolution of hominids. Ancient history and medieval history reveal that African trypanosomiasis affected the lives of people living in sub-Saharan African at all times. Modern history of African trypanosomiasis revolves around the identification of the causative agents and the mode of transmission of the infection, and the development of drugs for treatment and methods for control of the disease. From the recent history of sleeping sickness we can learn that the disease can be controlled but probably not be eradicated. Current history of human African trypanosomiasis has shown that the production of anti-sleeping sickness drugs is not always guaranteed, and therefore, new, better and cheaper drugs are urgently required

Tangwa, Godfrey B. \& Nchangwi Syntia Munung (2020): COVID-19: Africa's relation with epidemics and some imperative ethics considerations of the moment. First Published June 27, 2020 ------ COVID-19 is a very complex pandemic. It has affected individuals, different countries and regions of the world equally in some senses and differently in other senses. While sub-Saharan Africa has weathered a range of outbreaks of emerging and re-emerging infectious diseases, the manner in which the COVID-19 pandemic has evolved necessitates some observations, remarks and conclusions from our own situated observation point. Compared to previous epidemics/pandemics, many African countries have displayed a sense of solidarity in the face of COVID-19 that convincingly demonstrates that an Ubuntu ethic is viable and globalizable. The African continent seems, at last, to have realized that ethics dumping must be avoided and has made strides in defining its COVID-19 research agenda and strengthening its epidemic response for both public health and health research. More needs to be done in terms of public engagement, funding and technical support for research on potential therapies/candidate vaccines that are a product of scientific studies on the continent.

Tilley, Helen (2016): Medicine, Empires, and Ethics in Colonial Africa. AMA J Ethics. 2016;18(7):743-753 ------- This essay examines the history of European empire building and health 
work in sub-Saharan Africa, focusing on four patterns that shed light on the ethics of outside interventions: (1) the epidemiological and bodily harms caused by conquest and economic development; (2) the uneven and inadequate health infrastructures established during the colonial era, including certain iatrogenic consequences; (3) the ethical ambiguities and transgressions of colonial research and treatment campaigns; and (4) the concerted and inadvertent efforts to undermine African healing practices, which were not always commensurable with introduced medical techniques. This kind of historical analysis helps us home in on different kinds of ethical problems that have grown out of past asymmetries of power-between people, professions, states, and institutions - that shape the nature of international health systems to this day. What do we learn about ethics and international health systems when we look to the past? This essay considers this question by examining the history of colonialism in sub-Saharan Africa, focusing on the harms of conquest and on the treatment and research campaigns sponsored by nascent medical services. At over 11 million square miles, Africa is the second-largest continent (after Asia) and was the last massive region of the world that Europeans colonized (between 1880 and 1910). The timing and scale of European colonization matter. This was a period when germ theories of disease began to predominate in many parts of the world and pharmaceutical treatments and vaccination campaigns were on the rise [1, 2]. It was also a time when hygienic regimes in cities became more uniform [3]. These new ideas and techniques increased people's faith that diseases could be mastered and human lives extended, if only the new knowledge were applied. By exploring the ethical dimensions of medicine in colonial Africa, we can begin to appreciate the moral complexity not only of past interventions but also of international health systems today, given their roots in imperial dynamics. Indeed, historical analysis of the unintended-and the willful-harms produced during the colonial period bring to light various lessons for the present since these patterns linger and continue to affect people's perceptions and practices.

UNDP (2021): Long-Term Socio-Economic Impacts of COVID-19 in African Contexts. UNDP, March 11, 2021 --- The COVID-19 pandemic has claimed over 100,000 African lives and nearly 4 million cases have been recorded so far. Africa's COVID-19 story is one of nuances. Only 10 countries account for over $80 \%$ of all cases, island nations suffer peculiar impacts, rural-urban differentiation is evident, socioeconomic implications reveal gender biases, and trade patterns matter. There is no single Africa COVID-19 story. Addressing COVID-19 in Africa and designing appropriate remedial strategies requires a thorough understanding of Africa's diverse contexts and an appreciation of the role of regional integration in defining solutions.

UNESCO (2020): Socio-economic and cultural impacts of COVID-19 on Africa. United Nations Educational, Scientific and Cultural Organization ----- . The COVID-19 outbreak is a global public health crisis. It resonates deeply also at the heart of UNESCO's mission. COVID-19 tells us scientific cooperation is key when dealing with a global public health issue. It tells us that continued education must be ensured when so many children today cannot go to school. It is a stark reminder of the importance of quality, reliable information, at a time when rumors are flourishing. It tells about the power of culture \& knowledge to stren-gthen human fabric and solidarity, at a time when so many people around the world must keep social distance and stay at home. UNES-CO is fully committed to supporting governments for distance learning, open science, knowledge and culture sharing, as fundamental means to stand together and tighten the bonds of our shared humanity.

Ugwu, Daniel S. (2009): Socio-Economic Impact of HIV/AIDS on Farm Women in Nigeria: Evidence from Enugu State. World Applied Sciences Journal 6 (12): 1617-1624, 2009ISSN 1818-4952 ---- Most recently, the role of women in the development of agriculture and other sectors of the Nigerianeconomy have been acknowledged and recorded. Women contribute significantly in agriculture, ruraldevelopment and biodiversity conservation. Women are known to produce up to $60 \%$ of the food consumedby the backbone of subsistence agriculture in the developing countries. The rural women are the principalactors in pre-and-post-harvest food processes as processors, preservers, preparers and distributors [26].Women also engage in animal husbandry involving keeping and tending of small ruminants (sheep and goats)and poultry to supplement family income and nutrition. Among the pastoral Fulani in Nigeria, women tendcalves, milk cows, process milk and prepare milk products for sale as well as for consumption. Despite thesignificant contributions of women to agricultural development in Nigeria as enunciated above, the impact ofthe HIV/AIDS epidemic on farm women have not been empirically investigated or documented. The primaryobjective of this study was to examine and determine the impact of HIV/AIDS on farm women in Nigeria withparticular reference to Enugu State. Multi-stage and purposive sampling methodologies were employed in theselection of farm families/households including (women) persons living with HIV/AIDS (PLWHAs) and(women) persons affected with HIV/AIDS (PABA) for the study. Sixty (60) farm women/PLWHAs/PABA andsixty (60) uninfected farm women/households were purposively sampled for the study. The results of the studyshowed that the impact of HIV/AIDS on the farm women and their households were significant. These were withrespect to loss of feminine agricultural labour supply, reduced household income, reduced agriculturalproduction, increased family burden as well as loss of family assets and the women's right, among others. Itwas recommended that there is the need for a gender-based 
paradigm to agricultural and rural development inNigeria in view of the fact that women are at the centre stage of the HIV/AIDS epidemic in Nigeria.

Tong, Jaceline \& Olaf Valverde et al. (2011): Challenges of controlling sleeping sickness in areas of violent conflict: experience in the Democratic Republic of Congo. Confl Health 5 , 7 (2011). https://doi.org/10.1186/1752-1505-5-7 ---- In conflict settings where HAT is prevalent, targeted medical interventions are needed to provide care to the patients caught in these areas. Strategies of integrating care into existing health systems may be unfeasible since such infrastructure is often absent in resource-poor contexts. HAT care in conflict areas must balance logistical and medical capacity with security considerations, and community networks and international-response coordination should be maintained. Research and development for less complicated, field-adapted tools for diagnosis and treatment, and international support for funding and program implementation, are urgently needed to facilitate HAT control in these remote and insecure areas.

Vanderslott, Samantha \& Tatjana Marks (2020): Health diplomacy across borders: the case of yellow fever and COVID-19. Journal of Travel Medicine, Volume 27, Issue 5, July 2020, Published: 08 July 2020 ---- The measures deployed for halting the international spread of disease have varied considerably over time. The case of one disease-yellow fever-provides an insight into the evolution of public health interventions from which to see the health diplomacy implications of how global health and international relations interact and influence each other. Yellow fever is an infectious disease caused by a mosquito-borne flavivirus that occurs mostly in South America and sub-Saharan Africa. However, it used to be more widespread across the world, including parts of North America and could potentially spread to countries in Asia and the Caribbean. These countries are not currently endemic, but the mosquito vector Aedes aegypti and non-human primate hosts are present. I In controlling yellow fever, the early application of quarantine later shifted to more co-ordinated approaches, which today include country vaccine entry requirements. Public health interventions directed at yellow fever have always been closely intertwined with economic and foreign-policy interests and frequently led to diplomatic tensions in the past, beginning with quarantines.

Wade, Lizzie (2020): From Black Death to fatal flu, past pandemics show why people on the margins suffer most. ScienceMag.org , American Association for the Advancement of Sience (AAAS), ------- When the Black Death arrived in London by January 1349, the city had been waiting with dread for months. Londoners had heard reports of devastation from cities such as Florence, where $60 \%$ of people had died of plague the year before. In the summer of 1348, the disease had reached English ports from continental Europe and begun to ravage its way toward the capital. The plague caused painful and frightening symptoms, including fever, vomiting, coughing up blood, black pustules on the skin, and swollen lymph nodes. Death usually came within 3 days. The city prepared the best way it knew how: Officials built a massive cemetery, called East Smithfield, to bury as many victims as possible in consecrated ground, which the faithful believed would allow God to identify the dead as Christians on Judgment Day. Unable to save lives, the city tried to save souls.

Walsh, Bryan (2020): Covid-19: The history of pandemics. BBC (London). 26th March 2020 ------ Throughout history, nothing has killed more human beings than infectious disease. Covid-19 shows how vulnerable we remain - and how we can avoid similar pandemics in the future.

Whiteside, Alan (2002): Poverty and HIV/AIDS in Africa. Third World Quarterly, Volume 23, 2002 - Issue 2, pp. 313-332 ---- HIV/AIDS is the major threat to development, economic growth and poverty alleviation in much of Africa. And yet the full extent of the catastrophe facing the continent is only just being recognised, and still not by all. The international development targets set by the great and the good of the global community--or at least by those members of the community who attend the international summits that set these goals--do not consider what HIVIAIDS means and are unachievable. This paper begins by setting the scene, describing the epidemic, explaining why it is so important and what makes HIV/AIDS different. It then explores how the poverty/epidemic cycle works, whereby poverty increases the spread of HIV and AIDS increases poverty. It suggests we need to look beyond monetary poverty to understand these relationships. Finally the paper assesses what can and should be done to break the HIV/AIDS poverty cycle.

WHO (2020): Elimination of human onchocerciasis: progress report, 2019-2020. World Health Organization 6 November 2020 ---- Onchocerciasis is a parasitic infection caused by the filarial nematode Onchocerca volvulus. It is commonly called "river blindness", because the parasite is trans-mitted through the bites of blackflies of the genus Simulium that breed along rivers and streams in areas where there is fast-moving water and because infection with the parasite can result in vision loss and blindness. Currently, about 218 million people live in areas known to be endemic for onchocerciasis. For many, however, there is little risk for onchocerciasis-related blindness or skin disease as long as mass drug 
administration (MDA) with ivermectin continues. Four countries have completed the WHO-recommended process for verification of the interruption of transmission of human onchocerciasis, and many others have stopped MDA, completed post-treatment surveillance (PTS) or both in at least one transmission area in their territory. Interruption of transmission allows countries to protect the gains made during many years of effective MDA with ivermectin and to stop MDA permanently, freeing populations from the risk of morbidity and infection. Elimination of human onchocerciasis would make a meaningful contribution to Sustainable Development Goal (SDG) 3.3, which includes a call to end the epidemic of neglected tropical diseases (NTDs) by 2030.

Wilkie, David S. et al (2005): Role of Prices and Wealth in Consumer Demand for Bushmeat in Gabon, Central Africa. Conservation Biology, Volume19, Issue1, pp. 268-274 Unsustainable hunting of wildlife for food is often a more immediate and significant threat to the conservation of biological diversity in tropical forests than deforestation. Why people eat wildlife is debated. Some may eat bushmeat because they can afford it; others may eat it because it is familiar, traditional, confers prestige, tastes good, or adds variety. We completed a survey of 1208 rural and urban households in Gabon, Africa, in 2002-2003 to estimate the effect of wealth and prices on the consumption of wildlife and other sources of animal protein. Consumption of bushmeat, fish, chicken, and livestock increased with increasing household wealth, and as the price of these commodities rose, consumption declined. Although the prices of substitutes for bushmeat did not significantly, in statistical terms, influence bushmeat consumption, as the price of wildlife increased and its consumption fell, the consumption of fish rose, indicating that fish and bushmeat were dietary substitutes. Our results suggest that policy makers can use economic levers such as taxation or supply reduction through better law enforcement to change demand for wildlife. These measures will help to regulate unsustainable exploitation and reduce the risk of irreversible loss of largebodied and slow-reproducing wildlife species. If policy makers focus solely on reducing the unsustainable consumption of wildlife, they may see adverse impacts on the exploitation of fish. Furthermore, policy makers must ensure that raising household wealth through development assistance does not result in undesirable impacts on the conservation status of wildlife and fish.

Williamson, Ryan (2020): Corona pandemic's effect on state, presidential elections in the US. Auburn University, Auburn, Alabama ------- With nearly 20 states delaying primary elections, mail-in ballots a widely debated topic and a presidential election on the horizon, the country's political landscape has been greatly affected by the COVID-19 pandemic. Assistant Political Science Professor Ryan Williamson looks at the ways this year's elections have been impacted, how voters and candidates will be affected as a result of the ripple effect from the coronavirus and how future elections may be influenced for years to come. 


\section{Résumé:}

Sur l'impact socio-économique des pandémies en Afrique - Leçons tirées du COVID-19, de la trypanosomiase, du VIH, de la fièvre jaune, du choléra

Au cours de l'histoire, rien n'a tué plus d'êtres humains que les maladies infectieuses et la fièvre hémorragique. Bien que les taux de mortalité dus aux pandémies aient chuté de près de $1 \%$ par an dans le monde, environ $0,8 \%$ par an, tout au long du XXe siècle, le nombre de nouvelles maladies infectieuses comme le Sars, le VIH et le Covid-19 a presque quadruplé par rapport au passé. En Afrique, on a signalé un total de 4522489 cas confirmés de COVID-19 et 119816 décès, au 23 avril 2021. La pandémie a eu de graves répercussions sur les secteurs économique et social dans presque tous les pays africains. Il menace de pousser jusqu'à 58 millions de personnes dans l'extrême pauvreté. Cependant, outre les Africains pauvres, la pandémie de Covid affecte également la classe moyenne africaine en pleine croissance, c'est-à-dire environ 170 millions sur les 1,3 milliard d'africains actuellement classés dans la classe moyenne. Près de huit millions d'entre eux pourraient être plongés dans la pauvreté à cause du coronavirus et de ses conséquences économiques. Ce revers se fera sentir pendant des décennies. En outre, dans l'histoire récente de l'Afrique, d'autres maladies infectieuses comme la trypanosomiase du bassin du Congo de 1896 à 1906 avec un nombre des morts de plus de 500000 ainsi que l'épidémie de trypanosomose africaine en Ouganda de 1900 à 1920 avec 200000 à 300000 décès ont eu un impact négatif considérable sur les sociétés et économies africaines. En fait, d'autres pandémies, comme la fièvre jaune, le choléra, la méningite et la rougeole - sans parler du paludisme - ont contribué à des ralentissements économiques durables et affectent gravement le bienêtre social pendant des décennies. 